Cochrane Database of Systematic Reviews

\title{
Tailored interventions based on sputum eosinophils versus clinical symptoms for asthma in children and adults (Review)
}

Petsky HL, Li A, Chang AB

Petsky HL, Li A, Chang AB.

Tailored interventions based on sputum eosinophils versus clinical symptoms for asthma in children and adults.

Cochrane Database of Systematic Reviews 2017, Issue 8. Art. No.: CD005603.

DOI: 10.1002/14651858.CD005603.pub3.

www.cochranelibrary.com 
TABLE OF CONTENTS

HEADER

ABSTRACT

PLAIN LANGUAGE SUMMARY

SUMMARY OF FINDINGS

Figure 1.

Figure 2.

BACKGROUND

OBJECTIVES

METHODS

Figure 3.

RESULTS

Figure 4.

DISCUSSION

AUTHORS' CONCLUSIONS

ACKNOWLEDGEMENTS

REFERENCES

CHARACTERISTICS OF STUDIES

DATA AND ANALYSES

Analysis 1.1. Comparison 1 Asthma treatment tailored on sputum esoinophils versus symptoms, Outcome 1 Occurrence of any exacerbation.

Analysis 1.2. Comparison 1 Asthma treatment tailored on sputum esoinophils versus symptoms, Outcome 2 Number of participants who had one or more exacerbations over the study period.

Analysis 1.3. Comparison 1 Asthma treatment tailored on sputum esoinophils versus symptoms, Outcome 3 Number of participants with exacerbations regarding hospitalisations over the study period.

Analysis 1.4. Comparison 1 Asthma treatment tailored on sputum esoinophils versus symptoms, Outcome 4 Number of severe exacerbations requiring oral corticosteroids.

Analysis 1.5. Comparison 1 Asthma treatment tailored on sputum esoinophils versus symptoms, Outcome 5 MIld exacerbations over study period.

Analysis 1.6. Comparison 1 Asthma treatment tailored on sputum esoinophils versus symptoms, Outcome 6 Eosinophilic v Noneosinophilic exacerbations.

Analysis 1.7. Comparison 1 Asthma treatment tailored on sputum esoinophils versus symptoms, Outcome 7 Exacerbations subgrouped by asthma severity: Mild vs Severe.

Analysis 1.8. Comparison 1 Asthma treatment tailored on sputum esoinophils versus symptoms, Outcome 8 Exacerbations subgrouped by asthma severity: Use of LABA.

Analysis 1.9. Comparison 1 Asthma treatment tailored on sputum esoinophils versus symptoms, Outcome 9 Mean dose of inhaled corticosteroids per person per day (Bud equiv).

Analysis 1.10. Comparison 1 Asthma treatment tailored on sputum esoinophils versus symptoms, Outcome 10 Mean dose of oral corticosteroids per person per day.

Analysis 1.11. Comparison 1 Asthma treatment tailored on sputum esoinophils versus symptoms, Outcome 11 Yearly cost per person (USD).

ADDITIONAL TABLES

APPENDICES

WHAT'S NEW

HISTORY

CONTRIBUTIONS OF AUTHORS

DECLARATIONS OF INTEREST

SOURCES OF SUPPORT

DIFFERENCES BETWEEN PROTOCOL AND REVIEW

INDEX TERMS 
[Intervention Review]

\section{Tailored interventions based on sputum eosinophils versus clinical symptoms for asthma in children and adults}

Helen L Petsky ${ }^{1}$, Albert Li², Anne B Chang 3

1School of Nursing and Midwifery, Griffith University and Menzies Health Institute Queensland, Griffith University, Brisbane, Australia. 2Department of Paediatrics, Prince of Wales Hospital, Shatin, Hong Kong. ${ }^{3}$ Child Health Division, Menzies School of Health Research, Charles Darwin University, Darwin, Australia

Contact address: Helen L Petsky, School of Nursing and Midwifery, Griffith University and Menzies Health Institute Queensland, Griffith University, Brisbane, Queensland, Australia. helenpetsky@gmail.com.

Editorial group: Cochrane Airways Group.

Publication status and date: New search for studies and content updated (no change to conclusions), published in Issue 8, 2017.

Citation: Petsky HL, Li A, Chang AB. Tailored interventions based on sputum eosinophils versus clinical symptoms for asthma in children and adults. Cochrane Database of Systematic Reviews 2017, Issue 8. Art. No.: CD005603. DOI: 10.1002/14651858.CD005603.pub3.

Copyright ( 2017 The Cochrane Collaboration. Published by John Wiley \& Sons, Ltd.

\section{A B S T R A C T}

\section{Background}

Asthma severity and control can be measured both subjectively and objectively. Sputum analysis for evaluation of percentage of sputum eosinophilia directly measures airway inflammation, and is one method of objectively monitoring asthma. Using sputum analysis to adjust or tailor asthma medications is potentially superior to traditional methods based on symptoms and spirometry.

\section{Objectives}

To evaluate the efficacy of tailoring asthma interventions based on sputum analysis in comparison to traditional methods (usually symptom-based with or without spirometry/peak flow) for asthma-related outcomes in children and adults.

\section{Search methods}

We searched the Cochrane Airways Group Specialised Register of Trials, the Cochrane Central Register of Controlled Trials (CENTRAL), MEDLINE, Embase, trials' registries, and reference lists of articles. The last search was conducted in February 2017.

\section{Selection criteria}

All randomised controlled comparisons of adjustment of asthma therapy based on sputum eosinophils compared to traditional methods (primarily clinical symptoms and spirometry/peak flow).

\section{Data collection and analysis}

Results of searches were reviewed against pre-determined criteria for inclusion. In this update, two reviewers selected relevant studies, independently assessed trial quality and extracted the data. We contacted authors for further information when relevant. We analysed data as 'treatment received' and performed sensitivity analyses.

\section{Main results}

Three new studies were added in this update, resulting in a total of six included studies (five in adults and one involving children/ adolescents). These six studies were clinically and methodologically heterogeneous (use of medications, cut-off for percentage of sputum eosinophils and definition of asthma exacerbation). Of 374 participants randomised, 333 completed the trials. In the meta-analysis, there was a significant reduction in the occurrence of any exacerbations when treatment was based on sputum eosinophil counts, compared to that based on clinical symptoms with or without lung function; pooled odds ratio (OR) was 0.57 ( $95 \%$ confidence interval (CI) 0.38 to 0.86 ). 
The risk of having one or more exacerbations over 16 months was $82 \%$ in the control arm and $62 \%(95 \% \mathrm{Cl} 49 \%$ to $74 \%)$ in the sputum strategy arm, resulting in a number needed to treat to benefit (NNTB) of 6 ( $95 \% \mathrm{Cl} 4$ to 13$)$.

There were also differences between the groups in the rate of exacerbation (any exacerbation per year) and severity of exacerbations defined by requirement for use of oral corticosteroids and hospitalisations: the risk of one or more hospitalisations over 16 months was $24 \%$ in controls compared to $8 \%(95 \% \mathrm{Cl} 3 \%$ to $21 \%)$ in the sputum arm. Data for clinical symptoms, quality of life and spirometry were not significantly different between groups. The mean dose of inhaled corticosteroids per day was also similar in both groups. However sputum induction was not always possible. The included studies did not record any adverse events.

One study was not blinded and thus was considered to have a high risk of bias. However, when this study was removed in a sensitivity analysis, the difference between the groups for the primary outcome (exacerbations) remained statistically significant between groups. The GRADE quality of the evidence ranged from moderate (for the outcomes 'Occurrence of any exacerbation' and 'Hospitalisation' ) to low (for the outcome 'Mean dose of inhaled corticosteroids per person per day') due to the inconsistency in defining exacerbations and the small number of hospital admissions.

\section{Authors' conclusions}

In this updated review, tailoring asthma interventions based on sputum eosinophils is beneficial in reducing the frequency of asthma exacerbations in adults with asthma. Adults with frequent exacerbations and severe asthma may derive the greatest benefit from this additional monitoring test, although we were unable to confirm this through subgroup analysis. There is insufficient data available to assess tailoring asthma medications based on sputum eosinophilia in children.

Further robust RCTs need to be undertaken and these should include participants with different underlying asthma severities and endotypes.

\section{PLAIN LANGUAGE SUMMARY}

\section{Tailored interventions based on sputum eosinophils versus clinical symptoms for asthma in children and adults}

\section{Background}

Drug treatment for asthma is usually guided by various measures, such as asthma symptoms and lung function tests. In this review we wanted to find out if it was more beneficial to guide treatment according to sputum eosinophils. Eosinophils are a type of white blood cell that is increased in some forms of inflammation. The number of eosinophils in the sputum can tell us about levels of one type of inflammation in the lungs. We looked for evidence about whether measuring eosinophils in the sputum to guide asthma treatment improves asthma outcomes in children and adults.

\section{Study characteristics}

We included studies that compared adjustment of asthma medicines by counting sputum eosinophils versus usual care. To be included, the studies has to decide who would be in which group by chance. The participants all had asthma, diagnosed according to asthma guidelines.

The most recent search for studies was undertaken in February 2017.

This updated review includes six studies involving 382 people with asthma ( 55 children/adolescents, 327 adults). The studies varied in several ways including study duration and follow-up, sputum eosinophil counts used for adjusting medication and the way the asthma attacks were defined. Studies were between 6 and 24 months long. The age spread of participants in the studies was 12 to 48 years.

\section{Key results}

We found that guiding asthma medicines based on sputum eosinophil counts (compared to a control group) reduced the number and severity of asthma attacks in adults. In the control group where treatment was guided according to clinical symptoms, 82 participants out of 100 had at least one attack. This was reduced to 62 out of 100 in participants who had their medications guided by sputum eosinophil count. We are not certain about the effect on other measures, such as quality of life or dose of inhaled steroids needed. There is not enough data in children to assess whether using sputum eosinophil is useful.

\section{Quality of the evidence}

We are moderately confident in the evidence for any asthma attack and hospital admissions. We were concerned about the different ways the studies defined asthma attacks and the small number of hospital admissions overall, which makes it harder to detect a difference.

We are less confident in the evidence about the dose of inhaled steroids. This is because the studies used very different doses. Also, we cannot tell if the eosinophil-guided treatment reduced or increased the steroid dose overall. 


\section{SUMMARY OF FINDINGS}

Summary of findings for the main comparison. Tailored interventions based on sputum eosinophils compared to tailored interventions based on clinical symptoms for asthma in adults and children

Tailored interventions based on sputum eosinophils compared to tailored interventions based on clinical symptoms for asthma in adults and children

Patient or population: adults and children with asthma

Settings: hospital outpatients

Intervention: based on sputum eosinophils count

Comparison: based on clinical symptoms

\begin{tabular}{|c|c|c|c|c|c|c|}
\hline \multirow[t]{3}{*}{ Outcomes } & \multicolumn{2}{|c|}{ Illustrative comparative risks* $(95 \% \mathrm{Cl})$} & \multirow{3}{*}{$\begin{array}{l}\text { Relative effect } \\
(95 \% \mathrm{CI})\end{array}$} & \multirow{3}{*}{$\begin{array}{l}\text { No of Partici- } \\
\text { pants } \\
\text { (studies) }\end{array}$} & \multirow{3}{*}{$\begin{array}{l}\text { Quality of the } \\
\text { evidence } \\
\text { (GRADE) }\end{array}$} & \multirow[t]{3}{*}{ Comments } \\
\hline & $\begin{array}{l}\text { Assumed risk } \\
\text { at one year }\end{array}$ & Corresponding risk & & & & \\
\hline & $\begin{array}{l}\text { Tailored in- } \\
\text { terventions } \\
\text { based on clini- } \\
\text { cal symptoms }\end{array}$ & $\begin{array}{l}\text { Tailored interven- } \\
\text { tions based on sputum } \\
\text { eosinophils }\end{array}$ & & & & \\
\hline $\begin{array}{l}\text { Number of participants who had one or } \\
\text { more exacerbations over the study peri- } \\
\text { od }\end{array}$ & 82 per 100 & $\begin{array}{l}62 \text { per } 100 \\
(49 \text { to } 74)\end{array}$ & $\begin{array}{l}\text { OR } 0.36 \\
(0.21 \text { to } 0.62)\end{array}$ & $\begin{array}{l}228 \\
\text { (3 studies) }\end{array}$ & $\begin{array}{l}\oplus \oplus \oplus \odot \\
\text { moderate } 1\end{array}$ & see Figure 1 \\
\hline \multicolumn{7}{|l|}{ Follow-up: 12 to 24 months } \\
\hline $\begin{array}{l}\text { Hospitalisations } \\
\text { Follow-up: } 12 \text { to } 24 \text { months }\end{array}$ & 24 per 100 & $\begin{array}{l}8 \text { per } 100 \\
\text { ( } 3 \text { to } 21)\end{array}$ & $\begin{array}{l}\text { OR } 0.28 \\
\text { (0.09 to } 0.84)\end{array}$ & $\begin{array}{l}269 \\
\text { (4 studies) }\end{array}$ & $\begin{array}{l}\oplus \oplus \oplus \ominus \\
\text { moderate }\end{array}$ & see Figure 2 \\
\hline $\begin{array}{l}\text { Mean daily use of oral corticosteroids } \\
\text { per person per day } \\
\text { Follow-up: } 12 \text { months }\end{array}$ & See comment & See comment & Not estimable & $\begin{array}{l}68 \\
\text { ( } 1 \text { study) }\end{array}$ & & Not estimable \\
\hline $\begin{array}{l}\text { Yearly cost per person (USD) } \\
\text { Follow-up: } 12 \text { months }\end{array}$ & See comment & See comment & Not estimable & $\begin{array}{l}68 \\
\text { (1 study) }\end{array}$ & & Not estimable \\
\hline
\end{tabular}

$\omega$

Follow-up: 12 month 
"The basis for the assumed risk is the mean of the two studies with a duration of one year. The corresponding risk (and its $95 \%$ confidence interval) is based on the assumed risk in the comparison group and the relative effect of the intervention (and its $95 \% \mathrm{Cl}$ ).

Cl: Confidence interval; OR: Odds ratio;

\section{GRADE Working Group grades of evidence}

High quality: We are very confident that the true effect lies close to that of the estimate of effect.

Moderate quality: We are moderately confident in the effect estimate: The true effect is likely to be close to the estimate of effect but may be substantially different.

Low quality: Our confidence in the effect estimate is limited: The true effect may be substantially different from the estimate of effect.

Very low quality: We have very little confidence in the effect estimate: The true effect is likely to be substantially different from the estimate of effect.

1 One paper (Chlumsky 2006) was open labelled, but results were similar without this study. Our confidence in these results was downgraded by one point because of inconsistency in defining exacerbations

2 One paper (Chlumsky 2006) was open labelled, but did not contribute to this outcome. Our confidence in these results was downgraded by one point because of the small number of hospitalisations

3The dose of inhaled steroids varied considerably within and between studies and results are compatible with both important reduction or decrease in dose of inhaled corticosteroids using sputum eosinophils. 


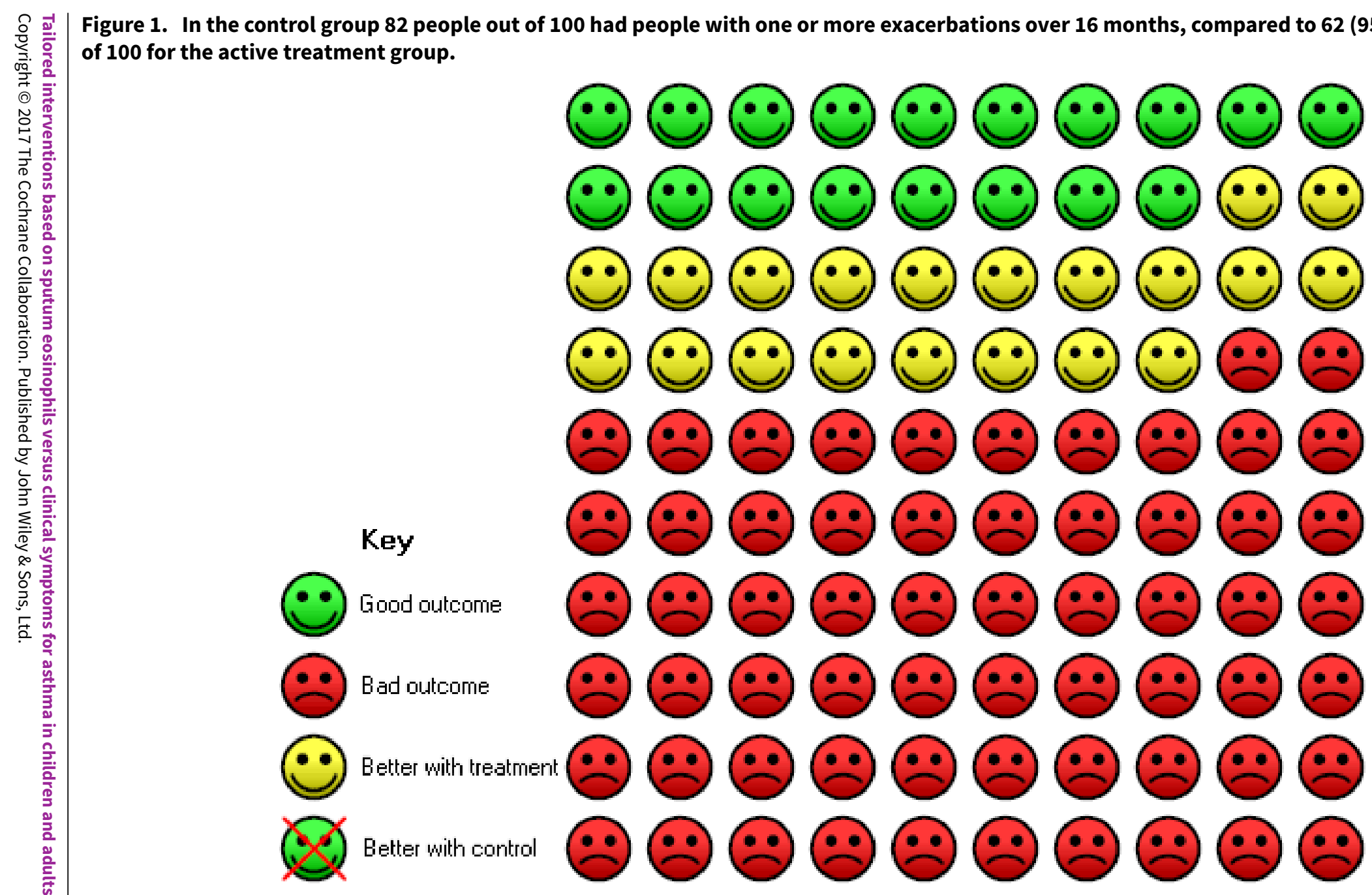




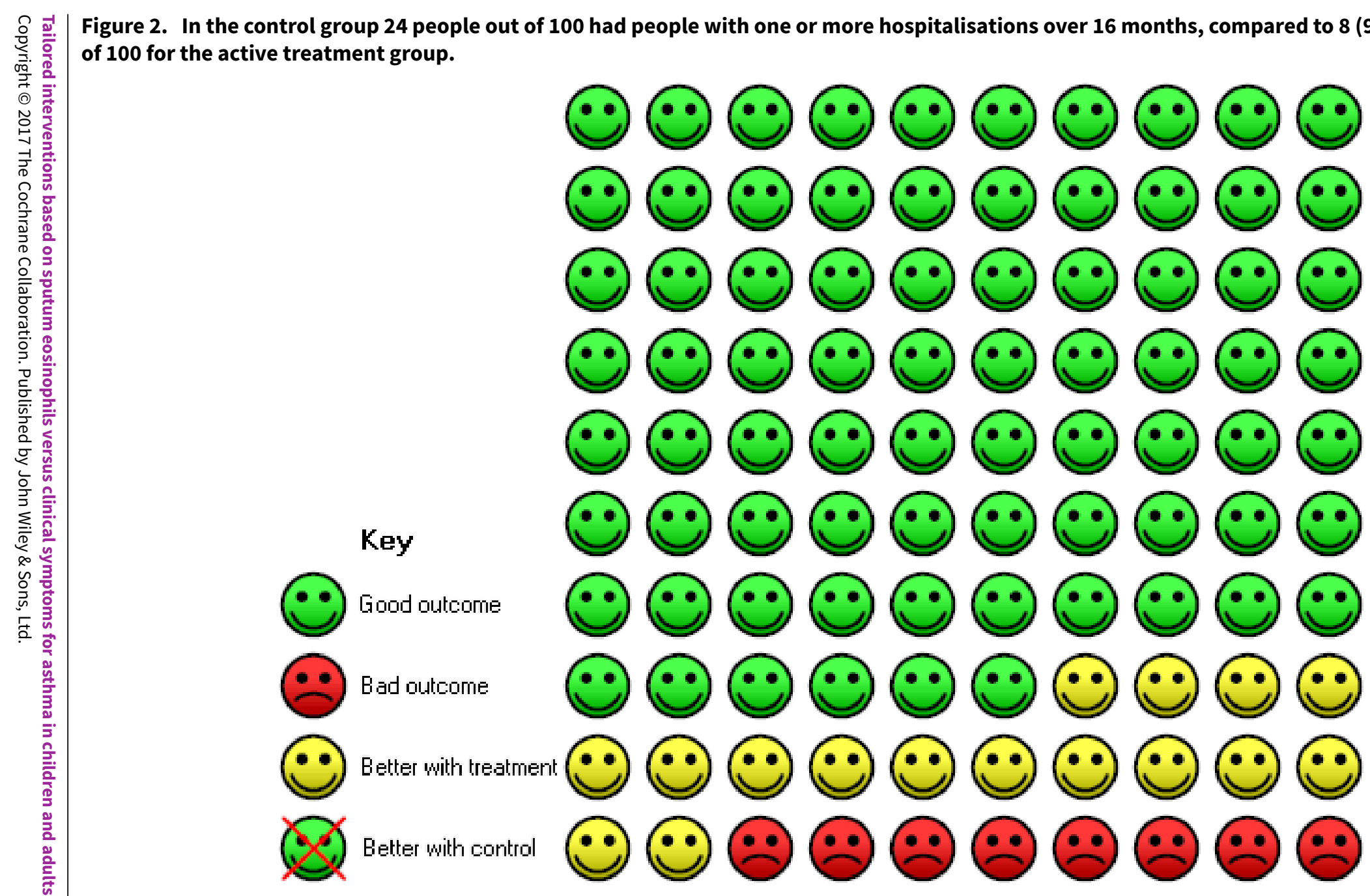




\section{B A C K G R O U N D}

\section{Description of the condition}

Asthma guidelines aim to guide health practitioners in adjusting treatment for patients so as to minimise symptoms or improve asthma control, optimise lung function, and prevent acute exacerbations (BTS/SIGN 2016; GINA 2017; National Asthma Council 2014). Exacerbations are important as they cause anxiety to patients and their families and are costly to healthcare systems (Weiss 2001). Preventing exacerbations is thus an important component for maintaining ideal asthma control. The second component in asthma management is monitoring of asthma control (by subjective and objective measures) (BTS/SIGN 2016; GINA 2017; National Asthma Council 2014). Subjective measures usually involve a series of questions used for clinical assessment, diary cards and quality-of-life questionnaires. Traditional objective measures include peak flow monitoring, spirometry and degree of airway hyper-responsiveness (AHR) (Zacharasiewicz 2005). Other methods such as markers of airway inflammation (e.g. sputum eosinophils, exhaled nitric oxide levels and breath condensate markers) have been advocated for asthma monitoring. These may be more sensitive markers than subjective measures, as they directly measure airway inflammation, in comparison to traditional objective measures (Zacharasiewicz 2005).

\section{Types of airway inflammation in people with asthma}

Airway inflammation in asthma may be eosinophilic, neutrophilic or a mixture of both (Douwes 2002). Asthma management is arguably best tailored in accordance with the type of airway inflammation, as corticosteroids are more beneficial in eosinophilic inflammation (Wardlaw 2000), and inhaled corticosteroids (ICS) reduce exacerbations and improve symptoms and asthma control (Wardlaw 2000).

\section{Description of the intervention}

There are several ways to quantify airway eosinophilic inflammation, such as determining the percentage of eosinophils in the sputum or in the bronchoalveolar lavage. Recurrent use of the latter is not feasible in clinical medicine as it is an invasive procedure (e.g. usually requiring general anaesthesia in children). Induced sputum is not invasive, it is much simpler to obtain sputum and it provides similar (but not identical) data to that of bronchoalveolar lavage. Induced sputum can be obtained by several methods including the use of nebulised hypertonic saline or mannitol (as part of a bronchial provocation testing) and chest physiotherapy techniques such as using airway clearance apparatus like the flute. The sputum obtained is then prepared and the total cell and differential cellularity determined, thereby providing the relative percentages of eosinophils, neutrophils and macrophages. Analysis of induced sputum is a reproducible method in determining airway inflammation in asthma in adults (Bacci 2002).

\section{How the intervention might work}

In many people with asthma, the percentage of eosinophils in induced sputum is higher than that in non-asthmatic patients (Ohnishi 1998). Neutrophilic airway inflammation has however also been described in people with asthma (Green 2002b). Thus assessing airway inflammation by quantitative measurements instead of subjective data potentially allows better tailoring of personal asthma interventions, which in turn may improve asthma control or reduce exacerbations, or both.

\section{Why it is important to do this review}

While tailoring asthma medications based on sputum eosinophilia may be helpful, undertaking induced sputum and sputum analysis is labour intensive and not widely available in non-research laboratories. Also, hypertonic saline or mannitol, used to induce sputum, may also temporarily increase asthma symptoms. Thus, a systematic review evaluating the efficacy of tailoring asthma interventions based on sputum analysis (sputum strategy, SS) in comparison with the traditional reliance primarily on clinical symptoms (CS) of asthma will be useful to help guide both physicians and patients as to whether or not undertaking this additional intervention is warranted in improving their asthma outcomes.

\section{O B JECTIVES}

To evaluate the efficacy of tailoring asthma interventions based on sputum analysis in comparison to traditional methods (usually symptom-based with or without spirometry/peak flow) for asthmarelated outcomes in children and adults.

\section{METHODS}

\section{Criteria for considering studies for this review}

\section{Types of studies}

All randomised controlled trials comparing adjustment of asthma medications based on sputum analysis in comparison to traditional methods (primarily clinical symptoms with or without spirometry/ peak flow).

\section{Types of participants}

Children and adults with a diagnosis of asthma in accordance to guideline-defined criteria. Exclusion criteria: eosinophilic bronchitis; asthma related to an underlying lung disease such as bronchiectasis and chronic obstructive pulmonary disease (COPD).

\section{Types of interventions}

We included studies which compared adjustment of asthma therapy based on sputum eosinophils to adjusting therapy based on clinical symptoms with or without spirometry/peak flow. Trials that included the use of other interventions were included if all participants had equal access to such interventions.

\section{Types of outcome measures}

\section{Primary outcomes}

Proportion of participants who had asthma exacerbations during follow-up.

\section{Secondary outcomes}

1. Objective measurements of asthma control $\left(\mathrm{FEV}_{1}\right.$, peak flow or airway hyper-responsiveness).

2. FeNO level.

3. Subjective symptoms as reported in Asthma Control Test or asthma-related quality of life questionnaire score.

4. Inhaled corticosteroid doses. 


\section{Cost analysis.}

We determined the proportions of participants who failed to improve on treatment and the mean clinical improvement using the following hierarchy of assessment measures (i.e. where two or more assessment measures are reported in the same study, we used the outcome measure that is listed first in the hierarchy).

1. Hospitalisation, acute presentations to an emergency facility for asthma, frequency of exacerbations and rescue courses of oral corticosteroids.

2. Symptomatic (quality of life, Likert scale, asthma diary, visual analogue scale) - assessed by the patient (adult or child).

3. Symptomatic (quality of life, Likert scale, asthma diary, visual analogue scale) - assessed by the parents/carers.

4. Symptomatic (Likert scale, visual analogue scale) - assessed by clinicians.

5. Indices of spirometry, peak flow, airway hyper-responsiveness.

6. Beta-agonist used.

\section{Search methods for identification of studies}

\section{Electronic searches}

This is an update of a previous Cochrane Review (Petsky 2007). For this update (from November 2008 to current search), we identified trials from the Cochrane Airways Group's Specialised Register (CAGR), which is maintained by the Information Specialist for the Group. The Register contains studies identified from several sources.

1. Monthly searches of the Cochrane Central Register of Controlled Trials (CENTRAL) in the Cochrane Library, through the Cochrane Register of Studies Online (crso.cochrane.org).

2. Weekly searches of MEDLINE Ovid SP 1946 to date.

3. Weekly searches of Embase Ovid SP 1974 to date.

4. Monthly searches of PsycINFO Ovid SP.

5. Monthly searches of CINAHL EBSCO (Cumulative Index to Nursing and Allied Health Literature).

6. Monthly searches of AMED EBSCO (Allied and Complementary Medicine).
7. Handsearches of the proceedings of major respiratory conferences.

Studies contained in the Trials Register are identified through search strategies based on the scope of Cochrane Airways. Details of these strategies, as well as a list of handsearched conference proceedings are in Appendix 1. See Appendix 2 for search terms used to identify studies for this review.

We also conducted a search of ClinicalTrials.gov (www.ClinicalTrials.gov) and the World Health Organization (WHO) trials portal (www.who.int/ictrp/en/), using the search strategy in Appendix 3. We searched all databases from their inception to 15 February 2017, and we imposed no restriction on language of publication.

\section{Searching other resources}

We checked reference lists of all primary studies and review articles for additional references. We searched relevant manufacturers' web sites for trial information.

We searched for errata or retractions from included studies published in full text on PubMed (www.ncbi.nlm.nih.gov/pubmed) on 10 March 2017.

\section{Data collection and analysis}

\section{Selection of studies}

The original selection of studies were reported in the previous review (Petsky 2007).

For this update, two review authors (HP, AC) independently screened titles, abstracts and descriptors retrieved from the literature searches, to identify potential relevant trials for inclusion. We retrieved potential full text study reports/publications and two review authors (HP, $\mathrm{AC}$ ) independently screened the full text and identified studies for inclusion, and recorded reasons for exclusion for ineligible studies. We identified and excluded duplicates and collated multiple reports of the same study so that each study, rather than each report, was the unit of interest in the review. We recorded the selection process in sufficient detail to complete the PRISMA flow diagram (Figure 3) and Characteristics of excluded studies table. 
Figure 3. Study flow diagram for 2008-2017 literature searches.
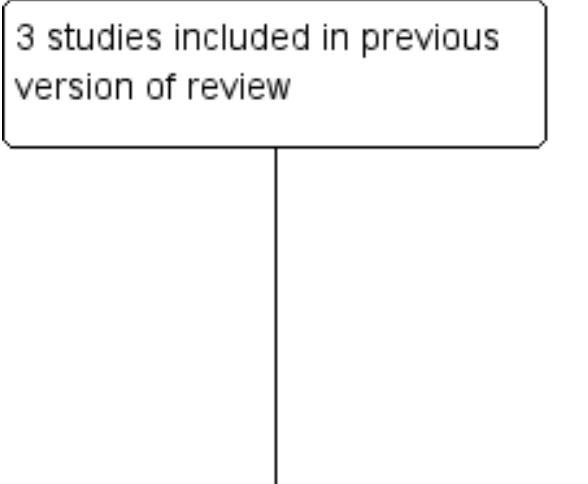

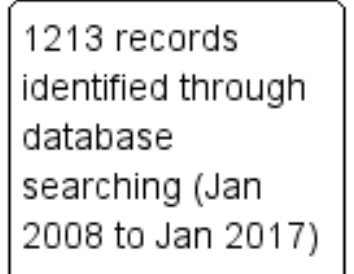

62 additional records identified through other sources
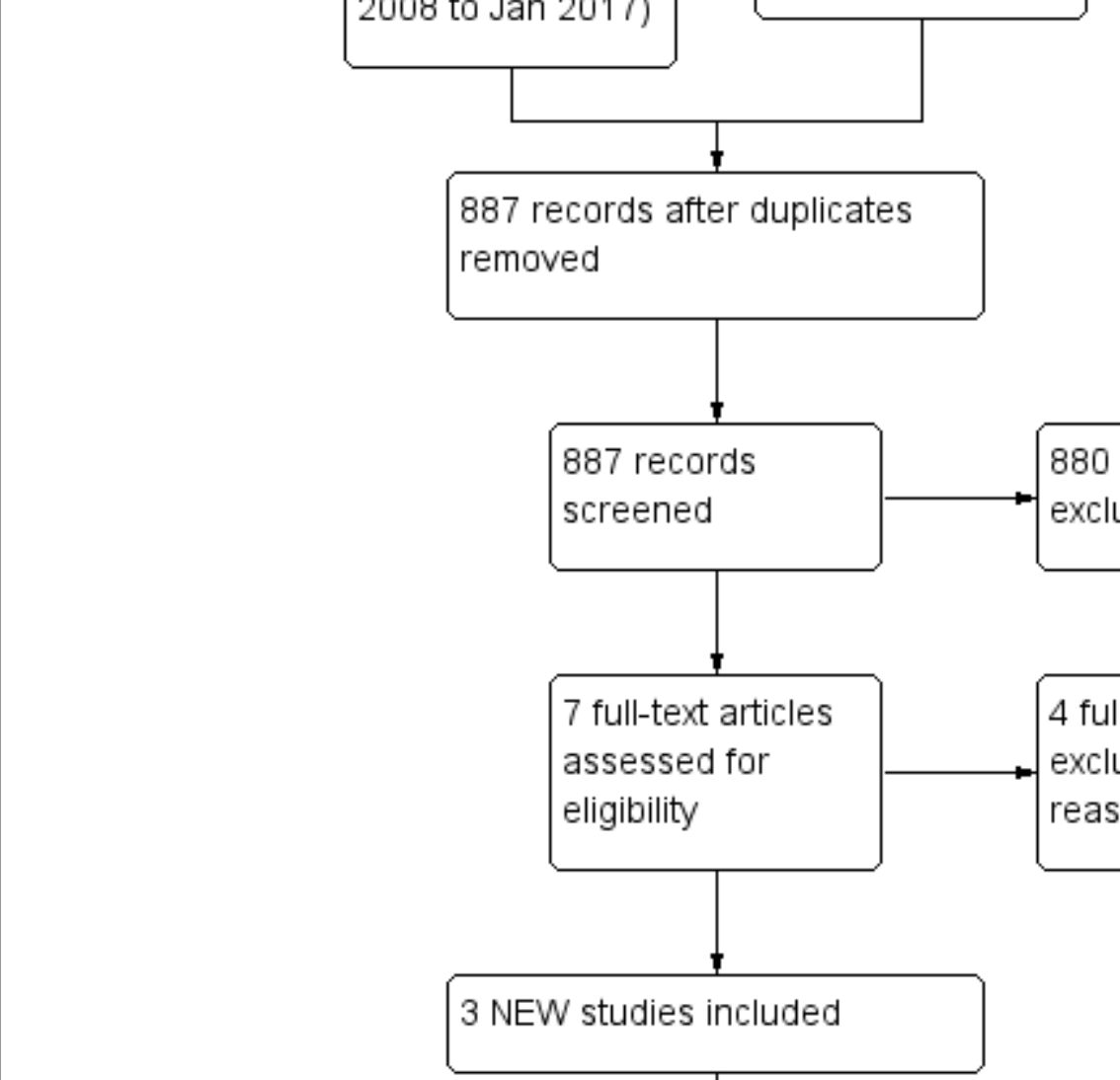

\section{removed}

880 records

excluded

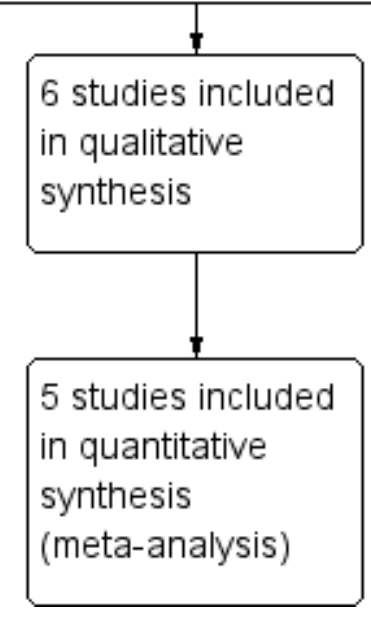

\section{Data extraction and management}

We reviewed trials that satisfied the inclusion criteria and recorded the following information: study setting, year of study, source of funding, patient recruitment details (including number of eligible participants), inclusion and exclusion criteria, other symptoms, randomisation and allocation concealment method, numbers of participants randomised, blinding (masking) of participants, care providers and outcome assessors, dose and type of intervention, duration of therapy, co-interventions, numbers of participants not followed up, reasons for withdrawals from study protocol (clinical, side-effects, refusal and other), details on side-effects of therapy, and whether intention-to-treat analyses were possible.

Tailored interventions based on sputum eosinophils versus clinical symptoms for asthma in children and adults (Review) 
We extracted data on the outcomes described previously and we double-entered data from included studies into Review Manager 5 (RevMan 5) for meta-analysis (Review Manager 2014).

Initial attempts to contact the corresponding authors in the original review were not successful (Petsky 2007). Dr Fleming provided further information and clarified some queries for Fleming 2012.

\section{Assessment of risk of bias in included studies}

We subjected studies included in the review to quality assessment and entered the results in 'Risk of bias' tables. We assessed seven components, as follows.

- Random sequence generation.

- Allocation concealment.

- Blinding of the participants and personnel.

- Blinding of outcome assessment.

- Incomplete outcome data.

- Selective outcome reporting.

- Other bias.

We recorded each potential source of bias as high, low or unclear and provided a quote with a justification for our judgement in the 'Risk of bias' table. We then summarised the risk of bias judgements across different studies for each of the domains listed. Where information on risk of bias related to unpublished data or correspondence with a trialist, we noted this in the 'Risk of bias' table.

When considering treatment effects, we considered the risk of bias for the studies that contributed to that outcome.

\section{Measures of treatment effect}

We analysed dichotomous data as odds ratios (OR) and continuous data as mean difference (MD) or standardised mean difference (SMD) with 95\% confidence intervals (Cl). We then entered data presented as a scale with a consistent direction of effect.

We undertook meta-analyses where it was meaningful (i.e. if the treatments, participants and the underlying clinical question were similar enough for pooling to make sense).

We narratively described skewed data as medians and interquartile ranges.

Where multiple trial arms were reported in a single trial, we included only the relevant arms. If two comparisons (e.g. drug A versus placebo and drug $B$ versus placebo) were combined in the same reported result, we halved the control group to avoid double counting.

\section{Unit of analysis issues}

For dichotomous data, we reported the proportion of participants contributing to each outcome in comparison to the total number randomised. For rate ratios of common events whereby one participant may have more than one event, we used generic inverse variance (GIV) analysis. The rate ratios were taken from the published papers and the standard errors calculated from $\mathrm{Cls}$ or $P$ values published in the papers. We had planned for cross-over studies, to calculate the mean treatment differences from raw data, and variances extracted or imputed and entered as fixed-effect (GIV) outcome, to provide summary weighted differences and $95 \% \mathrm{Cls}$.

\section{Dealing with missing data}

We contacted investigators to verify key study characteristics and obtain missing numerical outcome data where possible (e.g. when a study was identified as abstract only). Where this was not possible, and the missing data were thought to introduce serious bias, we explored the impact of including such studies in the overall assessment of results by a sensitivity analysis.

\section{Assessment of heterogeneity}

We described any heterogeneity between the study results and tested it to see if it reached statistical significance using a $\mathrm{Chi}^{2}$ test. We planned to include the $95 \% \mathrm{Cl}$ estimated using a randomeffects model whenever there were concerns about statistical heterogeneity. Heterogeneity was considered significant when the $P$ value was less than 0.10 (Higgins 2011). We then used the $I^{2}$ statistic to measure heterogeneity among the trials in each analysis. If we identified substantial heterogeneity, we reported it and explored possible cause of prespecified subgroup analysis.

\section{Assessment of reporting biases}

We were unable to pool more than 10 trials, so did not create and examine a funnel plot to explore possible small-study and publication biases.

\section{Data synthesis}

We included the results from studies that met the inclusion criteria and reported the outcomes of interest in the subsequent metaanalyses. The summary weighted odds ratio and $95 \%$ confidence interval (fixed-effect model) were calculated (Review Manager 2014). For rate ratios of common events whereby one participant may have more than one event, generic inverse variance (GIV) was utilised. The rate ratios were taken from the published papers and the standard errors were calculated from confidence intervals or $P$ values published in the papers. It was planned that for crossover studies, mean treatment differences would be calculated from raw data, extracted or imputed and entered as fixed-effect GIV outcome, to provide summary weighted differences and 95\% confidence intervals. For cross-over trials, it was planned that only data from the first arm were included in meta-analysis if data were combined with parallel studies (Elbourne 2002). Numbers needed to treat for an additional beneficial outcome (NNTB) were calculated from the pooled OR and its $95 \% \mathrm{Cl}$ applied to a specified baseline risk using an online calculator (Cates 2008). The outcome indices were assumed to be normally distributed continuous variables so the mean difference in outcomes could be estimated (weighted mean difference). If studies reported outcomes using different measurement scales, we estimated the standardised mean difference.

\section{Subgroup analysis and investigation of heterogeneity}

We carried out the planned a priori sub-group analysis for adults versus children.

\section{Sensitivity analysis}

We planned sensitivity analyses to assess the impact of the potentially important factors on the overall outcomes. 
1. Variation in the inclusion criteria.

2. Differences in the medications used in the intervention and comparison groups.

3. Analysis using random-effects model.

4. Analysis by 'treatment received'.

5. Analysis by 'intention-to-treat'.

6. Analysis by study design-parallel and crossover studies.

\section{RE S U L T S}

\section{Description of studies}

See Characteristics of included studies; Characteristics of excluded studies; Characteristics of studies awaiting classification.

\section{Results of the search}

See Figure 3 for study flow diagram.

For this update, the searches identified 1213 potentially relevant titles from CAGR. We identified an additional 62 titles through searches of ClinicalTrials.gov and the WHO trials portal (who.int/ ictrp/en/). After assessing the abstracts, seven papers were obtained for consideration to be included into the updated review. Four papers were not relevant as treatment was not based on sputum eosinophils or non-randomised. From the searches conducted in 2014 an additional two papers (Chakir 2010; D'Silva 2008) were considered eligible but were the same participants from an already included study (Jayaram 2006). Please see our previous review for results of searches (Petsky 2007).

\section{Included studies}

This updated review now includes six studies (see Characteristics of included studies): three were from our previous review (Petsky 2007); and three are new to this review (Figure 3). The six studies involved 374 randomised participants with 333 completing the trials (Cao 2007; Chlumsky 2006; Fleming 2012; Green 2002a; Jayaram 2006; Malerba 2015).

Five papers were published in English and one study in Chinese (Cao 2007), which was translated by two independent translators using a standardised extraction form.

\section{Study design}

All six studies were parallel-group studies. One was a multi-centre study (Jayaram 2006); and the other five were uni-centre studies (Cao 2007; Chlumsky 2006; Fleming 2012; Green 2002a; Malerba 2015).

Three studies were double blind (Fleming 2012; Green 2002a; Jayaram 2006); two were single blind (Cao 2007; Malerba 2015); and one had no blinding (Chlumsky 2006).

All the included studies differed in a variety of ways including the control arm, intervention arm (i.e. cut-off used for sputum eosinophil percentage used to adjust medications), definition of exacerbations and duration of study. These differences have been outlined in Table 1.

Malerba 2015 partly fulfilled the inclusion criteria but their data were not included in the meta-analyses as their intervention strategy involved adjusting the medication based on both FeNO levels and sputum eosinophil counts.

\section{Participants}

The six studies had different inclusion criteria for the participants. All studies included participants with asthma.

Five studies involved only adult patients (Cao 2007; Chlumsky 2006; Green 2002a; Jayaram 2006; Malerba 2015). There was one study that included children (Fleming 2012).

\section{Sputum eosinophil strategy (SS)}

The intervention arm in the studies, although primarily based on sputum eosinophil percentage, also differed slightly. In two studies, anti-inflammatory treatment was based on maintaining sputum eosinophil count below $3 \%$ with a minimum dose of antiinflammatory treatment (Cao 2007; Green 2002a). In Jayaram and colleagues' study, medications were adjusted to keep sputum eosinophils to $2 \%$ or less using inhaled corticosteroids (Jayaram 2006). In Chlumsky and colleagues' study, medications were based on maintaining the sputum eosinophil count below $8 \%$ (Chlumsky 2006). The paediatric paper adjusted treatment to keep sputum eosinophils to less than $2.5 \%$ (Fleming 2012).

The intervention arm in Malerba and colleagues' study was based on maintaining FeNO levels at less than $20 \mathrm{ppb}$, in addition to keeping sputum eosinophil count below 3\% (Malerba 2015).

The intervention strategies used in the various trials are further described in Table 1.

\section{Clinical symptom strategy (CS)}

Four of the six studies utilised existing asthma guidelines to adjust treatment in the control group (Cao 2007; Chlumsky 2006; Green 2002a; Jayaram 2006). One study used participant-reported symptoms (Malerba 2015). The sole paediatric study used number of major exacerbations (defined by oral corticosteroid use) and short-acting beta $_{2}$-agonists (SABA) use in the preceding three months (Fleming 2012).

The control group strategies are described in Table 1.

\section{Outcomes}

All six studies used asthma exacerbations as their primary outcome (Cao 2007; Chlumsky 2006; Fleming 2012; Green 2002a; Jayaram 2006; Malerba 2015). However the definitions of exacerbation were different among the studies (Table 1). In addition to exacerbations, two studies included reported symptoms as the primary outcome (Fleming 2012; Malerba 2015).

The secondary outcomes also varied among the studies. Five studies used ICS doses (Cao 2007; Fleming 2012; Green 2002a; Jayaram 2006; Malerba 2015); four studies included spirometry (Cao 2007; Chlumsky 2006; Green 2002a; Malerba 2015); two studies included symptom scores (Cao 2007; Green 2002a); and two included FeNO levels (Green 2002a; Malerba 2015).

The study characteristics are described in the Characteristics of included studies table.

\section{Excluded studies}

We recorded the reasons for excluding 23 studies in the Characteristics of excluded studies table. The most common reason 
for exclusions were: treatment not adjusted according to sputum eosinophil counts (18 studies); and not an RCT (five studies).

The search in November 2008 revealed another abstract that can be included (Pinot 2008); the author was contacted for further information but this abstract was never written up in full publication.

Adverse events were not reported in any studies. We requested further information from the authors to allow data to be entered into RevMan 5 for meta-analysis. Fleming 2012 provided some raw data.

\section{Risk of bias in included studies}

The full details of risk of bias judgements are described under the 'Risk of Bias' section in the Characteristics of included studies table and summarised in Figure 4. Overall, the methodological quality of the included studies was good.

Figure 4. Methodological quality summary: review authors' judgements about each methodological quality item for each included study.

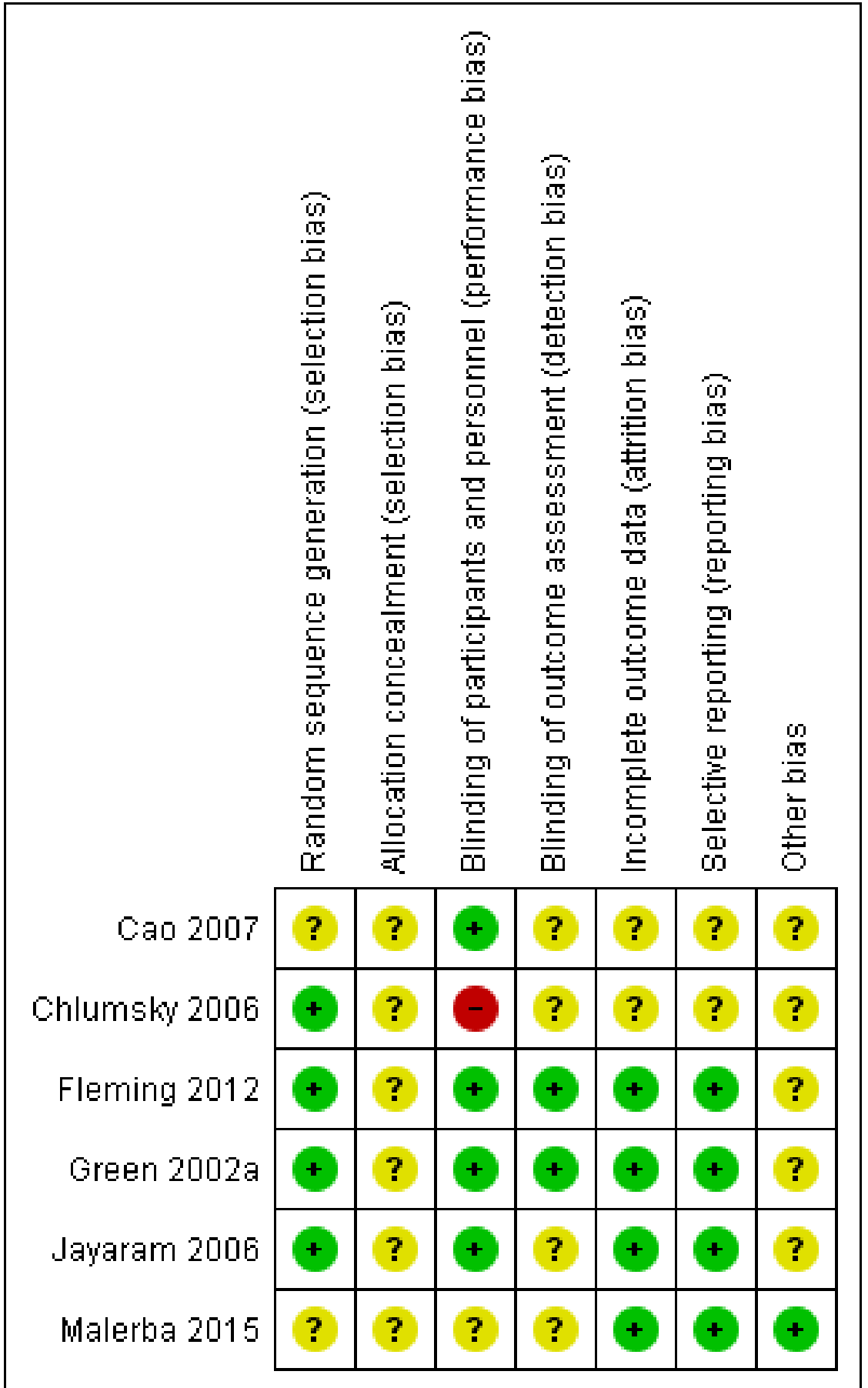

Tailored interventions based on sputum eosinophils versus clinical symptoms for asthma in children and adults (Review) 
Three studies were double blinded (Fleming 2012; Green 2002a; Jayaram 2006); whereas one was open labelled (Chlumsky 2006); and two single blinded (Cao 2007; Malerba 2015). Allocation concealment was clearly described in one study (Green 2002a), but unclear in the other five (Cao 2007; Chlumsky 2006; Fleming 2012; Jayaram 2006; Malerba 2015). All six studies reported on the progress of all randomised participants (Cao 2007; Chlumsky 2006; Fleming 2012; Green 2002a; Jayaram 2006; Malerba 2015).

\section{Allocation}

Four studies described generation of randomisation sequence (Chlumsky 2006; Fleming 2012; Green 2002a; Jayaram 2006); it was unclear in two single-blinded studies (Cao 2007; Malerba 2015). The method of allocation concealment was adequate in one study (Green 2002a), and unclear in five studies (Cao 2007; Chlumsky 2006; Fleming 2012; Jayaram 2006; Malerba 2015).

\section{Blinding}

Risk associated with participant blinding was low when the blinding of the assessors was reported based on information provided by the authors of the studies. These included comments from the studies such as "management decisions were made by independent physician" and "decisions made by an investigator blind to identity and randomisation group of the subject".

Risk of detection bias due to inadequate blinding of outcome assessors was high in one study (Chlumsky 2006); and unclear in two studies (Cao 2007; Malerba 2015), as there was not enough information in the published article. Three double-blinded studies were assessed at low risk of bias (Fleming 2012; Green 2002a; Jayaram 2006).

\section{Incomplete outcome data}

Four studies were at low risk of attrition bias (Fleming 2012; Green 2002a; Jayaram 2006; Malerba 2015). Two studies did not report on dropouts and were therefore judged at unclear risk of attrition bias (Cao 2007; Chlumsky 2006).

\section{Selective reporting}

Reporting bias was low in four studies with all outcomes being reported (Fleming 2012; Green 2002a; Jayaram 2006; Malerba 2015). Two studies were at unclear risk of reporting bias as there was inadequate information in the published article (Cao 2007; Chlumsky 2006).

\section{Other potential sources of bias}

Another source of bias was the success of obtaining sputum at each visit. Three studies did not report the success of sputum induction at each time point (Cao 2007; Chlumsky 2006; Malerba 2015). Three studies reported their success in sputum induction: Fleming 2012 reported $85 \%$ success in sputum induction; Green 2002a reported $87 \%$; and Jayaram 2006 reported $81 \%$ successful sputum induction.

\section{Effects of interventions}

See: Summary of findings for the main comparison Tailored interventions based on sputum eosinophils compared to tailored interventions based on clinical symptoms for asthma in adults and children
See: Summary of findings for the main comparison for the main comparisons.

\section{Asthma exacerbations}

All studies reported asthma exacerbations as the primary outcome (Cao 2007; Chlumsky 2006; Fleming 2012; Green 2002a; Jayaram 2006; Malerba 2015). The five adult studies described a significant reduction in asthma exacerbations in the arm that utilised treatment based on sputum eosinophils (SS) when compared to the clinical symptom (CS) arm (control arm whereby treatment was based primarily on clinical symptoms \pm lung function) (Cao 2007; Chlumsky 2006; Green 2002a; Jayaram 2006; Malerba 2015). The adult studies reported a significant difference between groups in exacerbation data, with the SS group experiencing fewer exacerbations than the CS group. The paediatric study did not find a significant difference in the number of exacerbation between the strategies for the study duration (Fleming 2012). However they did see a difference with smaller number of exacerbations being experienced in the sputum strategy group within 28 days of a study visit. Some but not all data that relate to exacerbations could be combined for meta-analysis. One study utilised FeNO levels in addition to sputum eosinophil counts to adjust medications in the intervention arm, therefore data from this study were not included in the meta-analyses (Malerba 2015).

Also, the definition of exacerbation of the studies differed as described in Table 1

\section{Any exacerbation (Outcome 1)}

\section{(a) Occurrence of any exacerbations (Analysis 1.1)}

Combining data from these four studies ( 3 adults and 1 children), the use of the symptom eosinophil strategy (SS), compared to the clinical symptom strategy (CS), significantly reduced the occurrence of any exacerbations: rate ratio was $0.57(95 \% \mathrm{Cl} 0.38$ to 0.86$) ; 269$ participants in four studies; $P=0.007$. As there was heterogeneity between the studies $\left(I^{2}=51 \%\right)$, we used a randomeffects analysis.

In subgroup analysis, we separated children from adult studies. In the adult-based studies ( $=3$ ), use of the sputum strategy (compared to controls) significantly reduced the rate ratio of occurrence of exacerbations: rate ratio was $0.45(95 \% \mathrm{Cl} 0.24$ to $0.86), 215$ participants in three studies; $P=0.02$. The heterogeneity remained high with $\mathrm{I}^{2}=55 \%$. In children there was only one study and there was no significant difference between the groups but the results numerically favoured the sputum strategy group: rate ratio was 0.75 ( $95 \% \mathrm{Cl} 0.54$ to 1.04); 54 participants; $\mathrm{P}=0.09$. The test for a difference between adults and children showed no statistical significance $\left(\mathrm{Chi}^{2}=1.93, \mathrm{df}=1(\mathrm{P}=0.17), \mathrm{I}^{2}=48.1 \%\right)$.

\section{(b) Number of participants who had one or more exacerbations (as defined by authors) during the study period (Analysis 1.2)}

Meta-analysis from data combined from four studies showed that the number of participants experiencing any exacerbation was significantly less $(P<0.001)$ in the SS group than in the CS group. Pooled OR estimate effect was $0.36(95 \% \mathrm{Cl} 0.21$ to 0.62$) ; 269$ participants. Using the combined control event rate from the oneyear studies of $82 \%$, the NNTB for 16 months was $6(95 \% \mathrm{Cl} 4$ to 13$)$; see Figure 1. 
When considering the adult studies only, the SS group had significantly fewer participants experiencing one or more exacerbations compared to the CS group: OR $0.36(95 \% \mathrm{Cl} 0.20$ to 0.64$) ; 215$ participants in 3 studies; $P<0.001$. However, the difference between the two groups in the paediatric study was not statistically significant: OR $0.39(95 \% \mathrm{Cl} 0.09$ to 1.71$) ; 54$ participants; $\mathrm{P}=0.21$. The test for a difference between adults and children showed no statistical significance $\left(\mathrm{Chi}^{2}=0.01, \mathrm{df}=1(\mathrm{P}=\right.$ $\left.0.92), I^{2}=0 \%\right)$.

\section{(c) Time to first exacerbation}

Four studies reported that the SS group had significantly longer time to first exacerbation compared to the CS group (Chlumsky 2006; Fleming 2012; Green 2002a; Jayaram 2006). However, the data from the studies could not be combined.

Chlumsky 2006 reported a significant difference $\left(\mathrm{Chi}^{2}=8.8, \mathrm{P}\right.$ $=0.003$ ). Green 2002a reported 12 exacerbations in the BTS management group in the first month, versus one in the sputum management group.

\section{Exacerbations classified by severity of exacerbation (Outcome 2)}

\section{(a) Number of participants requiring hospitalisation}

\section{See Analysis 1.3.}

None of the participants from either arm in Jayaram 2006 or Chlumsky 2006 were hospitalised, whereas a total of seven in Green 2002a and 13 in Fleming 2012 were hospitalised. Combined data showed a difference between the groups $(P=0.02)$ favouring the SS group: the OR was 0.28 (95\% $\mathrm{Cl} 0.09$ to 0.84$) ; 269$ participants in four studies. The risk of one or more hospitalisations over 16 months fell from a risk of $24 \%$ on control to $8 \%(95 \% \mathrm{Cl} 3 \%$ to $21 \%)$, giving a 16 month NNTB of 7 (95\% Cl 5 to 33); see Figure 2.

When considering only the adults who were hospitalised for subgroup analysis, the difference was no longer statistically significant $(\mathrm{P}=0.08)$; OR 0.14 ( $95 \% \mathrm{Cl} 0.02$ to 1.25$)$; 215 participants. Likewise statistical significance was lost when considering only children, $(\mathrm{P}=0.16)$ : OR $0.38(95 \% \mathrm{Cl} 0.10$ to 1.45$)$. The reduction in statistical power when considering subgroups of adults and children is the most likely reason for the loss of statistical significance in these subgroup findings.

\section{(b) Number of exacerbations requiring rescue oral corticosteroids (Analysis 1.4)}

The rate of exacerbations requiring treatment with rescue oral corticosteroids was significantly lower in the SS group compared to the CS group in one study (Jayaram 2006), rate ratio of $0.33(95 \% \mathrm{Cl}$ 0.16 to 0.70 ); 96 participants in one study, $P=0.004$.

\section{(c) Number of mild exacerbations (Analysis 1.5)}

Data on mild exacerbations were available in two studies (Fleming 2012; Jayaram 2006). As the definition of severe exacerbations (other than that defined in Analyses 1.3 and 1.4) differed between the studies it was difficult to combine this data. Combining the two studies which defined minor exacerbations similarly by loss of asthma control requiring more than four puffs extra of bronchodilators, the number of exacerbations between the groups reached borderline significance $(P=0.05)$ favouring $S S$, rate ratio of 0.82 (95\% Cl 0.67 to 1.00$)$; 150 participants.

\section{Eosinophilic exacerbations}

See Analysis 1.6.

Jayaram and colleagues reported types of asthma exacerbations in each group (Jayaram 2006). Sputum could only be obtained in 39 of the 47 exacerbations in the SS group and 63 of the 79 total exacerbations in the CS group. Those exacerbations where sputum could be obtained were classified as eosinophilic or non-eosinophilic and this indicated that the overall reduction in exacerbation rate was largely due to a reduction in eosinophilic exacerbations in this study.

\section{Exacerbations subgrouped by asthma severity}

\section{(a) Any exacerbation (risk ratio (RR)) by severity of asthma (Analysis 1.7)}

Five studies did not subgroup participants by asthma severity (Cao 2007; Chlumsky 2006; Fleming 2012; Green 2002a; Malerba 2015). Jayaram and colleagues analysed data based on daily requirement for ICS and long-acting beta ${ }_{2}$-agonists (LABA). Asthma severity was defined based on minimum daily maintenance fluticasone (mild asthma = requiring $<250 \mathrm{mcg} /$ day; moderate to severe asthma = requiring $250 \mathrm{mcg} /$ day) (Jayaram 2006). Those with mild asthma ( $<250 \mathrm{mcg} /$ day fluticasone equivalent) showed no significant difference: RR 1.34 (95\% Cl 0.52 to 3.46). Those with moderate to severe asthma ( $=250 \mathrm{mcg} /$ day fluticasone equivalent) also showed no significant difference between groups in the RR of exacerbation, although the direction of the outcome favoured the SS group (RR $0.63,95 \% \mathrm{Cl} 0.38$ to 1.04 ). The difference between these subgroup effects was not significant (test for subgroup differences: $\mathrm{Chi}^{2}{ }^{2}$ 1.93, $\mathrm{df}=1, \mathrm{P}=0.19$ ).

\section{(b) Any exacerbations (RR), by use of long-acting beta ${ }_{2}$-agonists (LABA) (Analysis 1.8)}

Green 2002a reported equal numbers of participants in both groups being treated with LABA $(N=12)$ but outcomes based on those on LABA were not available. Data from Jayaram 2006 did not show a significant difference between the effect on exacerbations in those taking LABA (RR $0.53,95 \% \mathrm{Cl} 0.25$ to 1.14 ) or those not on LABA (RR $1.05,95 \% \mathrm{Cl} 0.62$ to 1.78 ), (test for subgroup differences: $\mathrm{Chi}^{2} 2.07$, $\mathrm{df}=1, \mathrm{P}=0.15)$.

\section{Secondary outcomes}

Green 2002a reported other outcomes: exhaled nitric oxide was $48 \%$ lower in the SS group in comparison to the CS group at the end of study. The improvement in methacholine PC20 was significantly better in the SS group compared to the CS group at 6 months (doubling doses 1.0 versus $-0.7, P=0.03$ ) and 12 months $(0.2$ versus $-1.3, P=0.015)$. However, the visual analogue symptom scores, total asthma quality of life scores, peak expiratory flow amplitude (\% mean), FEV 1 after bronchodilator use and the use of rescue beta ${ }_{2}$-agonists did not differ significantly between the two groups in Green 2002a. Jayaram and colleagues did not report these outcomes; although asthma quality of life $(\mathrm{Q} o \mathrm{~L})$ assessments were undertaken, these results were not published (Jayaram 2006). Chlumsky et al's study also reported no significant difference between groups for $\mathrm{FEV}_{1}$ change and they did not report on symptoms or QOL (Chlumsky 2006). Fleming and colleagues reported that the FeNO levels did not significantly change over the study period (Fleming 2012). Both the SS and control groups had significant improvement in $\mathrm{FEV}_{1}$ scores when comparing z-score 
from end to beginning of the study. The mean (SE) difference was $0.51(0.37)$ for the symptom group and $0.49(0.34)$ for the sputum eosinophil group. Neither group had a significant change in their bronchodilator reversibility over the duration of the study (Fleming 2012).

\section{Mean daily dose of corticosteroid use}

\section{(a) Inhaled corticosteroid (ICS) (Analysis 1.9)}

All six studies reported no significant differences in ICS use between groups. The SD for the groups were not available in Jayaram 2006 and was imputed based on the data from Green 2002a. Forest plots showed no significant difference between the groups and a wide confidence interval. Pooled MD $12.56 \mathrm{mcg}(95 \% \mathrm{Cl}-127.92$ to 153.04).

\section{(b) Oral corticosteroids (Analysis 1.10)}

Only Green and colleagues reported on mean oral corticosteroids use and described no difference between the groups (mean difference of $-0.40 \mathrm{mg}, 95 \% \mathrm{Cl}-2.36$ to 1.56 ) (Green 2002a). Metaanalysis was not possible.

\section{Cost (Analysis 1.11)}

Green and colleagues described estimated cost per patient per year and there was no significant difference between the groups (mean difference of $-314,95 \% \mathrm{Cl}-941.27$ to 313.27 ) (Green 2002a). There were no data from other studies.

\section{Other results}

Sputum induction was not always successful: in Green's study, sputum induction was successful in 552 of 632 attempts (87\%) (Green 2002a), and 102 out of a total of $126(81 \%)$ in Jayaram and colleagues' study (Jayaram 2006). Fleming 2012, the one included paediatric paper, reported a success rate of $85 \%$ (174 occasions) with a sputum differential count success in 152 samples. Chlumsky 2006, Cao 2007 and Malerba 2015 did not report their success rate in obtaining sputum. No other adverse events were reported in the studies.

\section{Sensitivity analyses}

In the outcome of number of participants with one or more exacerbations during the study period, analyses based on 'intention to treat' (ITT) altered pooled OR only slightly from 0.49 $(95 \% \mathrm{Cl} 0.28$ to 0.87$)$ for 'treatment received' to $0.50(95 \% \mathrm{Cl} 0.28$ to 0.88$)$. The NNTB for one year changed from 6 (95\% $\mathrm{Cl} 4$ to 13) to 7 (95\% Cl 4 to 35). Re-analysis of the data based on the less conservative numbers (i.e. use of total of 102 as opposed to 96) for Jayaram and colleagues' study did not change the direction or significance of any of the outcomes (Jayaram 2006). Likewise re-analysis of data based on ITT did not alter direction or significance of effects. In the outcomes described above, significant heterogeneity was only found in subgroup comparisons and thus no sensitivity analyses were performed for this.

One study did not use blinding (Chlumsky 2006); however removing the data from this study did not alter the results of the primary outcome (exacerbations) found in the main analyses; occurrence of any exacerbation (RR $0.66,95 \% \mathrm{Cl} 0.46$ to 0.93 ; participants = 218; studies $=3$ ), number of participants who had one of more exacerbations over the study period (OR $0.43,95 \% \mathrm{Cl} 0.24$ to 0.79 ; participants $=218$; studies $=3$ ) and exacerbations requiring hospitalisations (OR $0.28,95 \% \mathrm{Cl} 0.09$ to 0.84 ; participants = 218; studies $=3$ ).

\section{DISCUSSION}

\section{Summary of main results}

This review consists of six RCTs involving 374 participants with 344 completing the trials. The studies varied in the sputum eosinophil levels (ranging from $2 \%$ to $8 \%$ ) and algorithms used to adjust medications. The duration of the studies also differed, ranging from 6 to 24 months. We found that asthma exacerbations decreased when treatment was adjusted according to sputum eosinophil percentage. Six participants would need to have their asthma treatment adjusted by sputum eosinophil count for one participant to avoid exacerbation ( $95 \% \mathrm{Cl} 4$ to 13). However, the data were robust for adult participants only as there was a single study involving children/adolescents. Also, there were no significant difference between the groups in symptoms of asthma (VAS score, QoL and beta agonist use) but this was limited by little data.

All studies reported exacerbations (our review's primary outcome), but the definition varied among the studies. We were able to combine data for a maximum of four studies for the meta-analysis of the different definitions of exacerbation. The occurrence of any exacerbation was significantly lower in the group that utilised sputum eosinophil counts compared to the symptom strategy (rate ratio $0.57,95 \% \mathrm{Cl} 0.38$ to 0.86 ). Likewise, the number of participants having one or more asthma exacerbations was lower in the sputum eosinophil group (OR $0.36,95 \% \mathrm{Cl} 0.21$ to 0.62 ). The number of people with exacerbations requiring hospitalisations was significantly lower in the sputum eosinophilia strategy (OR $0.28,95 \% \mathrm{Cl} 0.09$ to 0.84 ).

There was no significant difference between groups for the mean daily dose of inhaled corticosteroids at final visit.

In the subgroup analyses, for children the reductions seen between the sputum eosinophil strategy and control strategy for occurrence of any exacerbations (RR $0.75,95 \% \mathrm{Cl} 0.54$ to 1.04 ), number of participants who had one or more episodes of asthma exacerbation (OR $0.39,95 \% \mathrm{Cl} 0.09$ to 1.71 ) or exacerbations requiring hospitalisations (OR $0.38,95 \% \mathrm{Cl} 0.10$ to 1.45 ) did not achieve statistical significance (possibly due to lack of statistical power due to small numbers).

In the sensitivity analyses, there were no changes in the primary outcomes when conducting analyses on 'intention to treat' or by removing the one study which did not have any blinding (Chlumsky 2006).

\section{Overall completeness and applicability of evidence}

This review included six studies, but the meta-analyses consisted of data from between one to five studies for the various outcomes, including our review's primary outcome. The total number of participants for the various outcomes ranged from 68 (outcomes: mean dose of oral corticosteroids per person per day and yearly cost per person) to 316 (outcome: mean daily dose of inhaled corticosteroids per person per day). Although we contacted authors of the studies, the completeness of the review was limited by availability of data. 
Theoretically the use of sputum to guide asthma therapy may result in significant differences in doses of oral or ICS. This meta-analysis found that there was no significant differences in the amount of corticosteroids (inhaled or oral) used between the two groups. Also, Green 2002a reported that the annual cost was not significantly more expensive in the SS group compared to the CS group.

In contrast to the favourable data in the outcome of exacerbations that support the use of sputum to guide asthma therapies, there was a lack of difference between the groups in symptoms of asthma (VAS score, QoL and beta agonist use). While exacerbations are an important outcome, arguably subjective measures of asthma control are also important.

Asthma is a heterogeneous condition, and there is increasing appreciation of non-eosinophilic asthma (Seys 2017) and overlap syndromes (with COPD) (Karampitsakos 2016). The data from this review is unlikely to be applicable to those who have noneosinophilic asthma, overlap syndromes, or exacerbations that are non-eosinophilic asthma. Thus, although this meta-analysis that has shown that monitoring airway inflammation through eosinophils in induced sputum is useful in reducing exacerbations in adults, it is arguable that it cannot be universally advocated. However, in people with frequent exacerbations it is likely that this intervention is useful.

None of the studies used the new biologic compounds (e.g. antiinterleukin-5) that is efficacious for severe eosinophilic asthma in adults (Robinson 2017).

Furthermore, sputum analysis is restricted to laboratories with specific expertise in inducing and analysing sputum. Obtaining and analysing sputum is relatively time consuming (when compared to exhaled nitric oxide) and is not always successful. Also, it can be very difficult to obtain satisfactory samples in young children.

Lastly this review is limited in children as there was only one small study that included children (Fleming 2012).

\section{Quality of the evidence}

We summarised the evidence for the three main outcomes related to exacerbations and ICS dose in the 'Summary of findings' table. Overall, we judged the quality of evidence to be moderate for exacerbations (due to inconsistency of definition of an exacerbation) and hospitalisations (due to the small number of events). One study was a non-blinded trial but removing this study did not alter the results of the primary outcomes (Chlumsky 2006).

The quality of the evidence for the outcome of ICS dose per person per day at the end of the study was low. We downgraded this outcome by one for imprecision and one for lack of blinding in one study. The dose of inhaled steroids varied considerably within and between studies.

\section{Potential biases in the review process}

We are unaware of any bias in the review process. We used a comprehensive search strategy and adhered to the protocol. Two review authors (HP, AC) independently assessed the risk of bias. We contacted the corresponding authors of all the studies for raw data to include in the meta-analysis. AC and the review editor (Christopher Cates) independently checked the data extraction, 'Risk of bias' assessment, and downgrading decisions for the
'Summary of findings' table in order to minimise the risk of bias in the review process.

The inclusion of Malerba 2015 in the meta-analyses would have introduced bias, as the strategy used included FeNO in addition to sputum eosinophil counts.

\section{Agreements and disagreements with other studies or reviews}

This is an update of a previous Cochrane Review (Petsky 2007) and has been strengthened by the addition of three RCTs (Cao 2007; Fleming 2012; Malerba 2015). The findings of both Cochrane Reviews are in agreement, with fewer asthma exacerbations occurring in the group that had their asthma treatment adjusted based on sputum eosinophil percentage.

A recent literature review (Seys 2017) concluded that monitoring eosinophilic inflammation using sputum cell counts is helpful to monitor asthma severity, control and progression of disease.

\section{AUTHORS' CONCLUSIONS}

\section{Implications for practice}

The results from this review suggests that tailoring asthma interventions based on sputum eosinophils instead of primarily on clinical symptoms with or without spirometry/peak flow decreases frequency and severity of asthma exacerbations, especially eosinophilic exacerbations in adults. However, as data for clinical symptoms, QoL and spirometry were not different between groups, the value of the intervention in all settings is less clear at this time. Nevertheless, the findings of this review support the addition of sputum eosinophil measurement to traditional strategies to tailor asthma interventions in adult patients. Adults with frequent exacerbations and severe asthma may derive the greatest benefit from this additional monitoring test, although we were unable to confirm this through subgroup analysis. Studies using newer biologic compounds for eosinophilic diseases did not fulfil the inclusion criteria and hence this review cannot be extrapolated to these agents (e.g. anti-interleukin-5), Also, as data on children was restricted to a single study with no significant difference between groups for any outcomes, there is insufficient data for or against tailoring asthma medications based on sputum eosinophilia in children.

\section{Implications for research}

Further RCTs with groups stratified by asthma severity and type of airway inflammation (eosinophilic or neutrophilic) are required. The trials need to include children as well as adults. The design of future RCTs should preferably be multi-centre studies and include other objective measures of asthma including exhaled nitric oxide in addition to the sputum analysis and traditional outcomes of spirometry and peak flow. Subjective outcome measures should also be determined including scores for asthma control and quality of life. Analysis of costs and possible adverse events of inhaled and oral corticosteroids would also provide additional important information. New RCTs should also report the success rate of sputum induction/differential cell count and adverse events associated with sputum induction. 


\section{ACKN OWLEDGEMENTS}

We thank Toby Lasserson and Dr Chris Cates from the Cochrane Airways Group for their advice, supportive role and comments to the original protocol and review. In this updated review, we thank all the members of the Cochrane Airways Group, in particular Dr Chris Cates for his support and checking our analysis.

We are also very grateful to Elizabeth Stovold for performing the relevant searches and obtaining the articles.

We thank Xian-Tao Zeng and Yang Meng for translating the Chinese paper and completing the translation forms to enable this paper to be included (Cao 2007). We would also like to thank Dr Peter Wark, Dr Antoine Magnan and Dr Louise Fleming for their correspondence in replying to our queries. Finally we are grateful to the Australian Cochrane Airways Group and Scholarship for providing funding for HP to complete the original review.

Chris Cates was the Editor for this review and commented critically on the review.

The Background and Methods sections of this review are based on a standard template used by Cochrane Airways.

This project was supported by the National Institute for Health Research (NIHR), via Cochrane Infrastructure funding to the Cochrane Airways Group. The views and opinions expressed herein are those of the authors and do not necessarily reflect those of the Systematic Reviews Programme, NIHR, NHS, or the Department of Health. 


\section{RE F E R E N C E S}

\section{References to studies included in this review}

Cao 2007 \{published data only\}

* Cao WL, Sun YC, Yao WZ. A study on a therapeutic protocol to improve the control of persistent asthma by monitoring sputum eosinophil counts. Chung-Hua Chieh Ho Ho Hu Hsi Tsa Chih Chinese Journal of Tuberculosis \& Respiratory Diseases 2007;30(5):334-8.

\section{Chlumsky 2006 \{published data only\}}

Chlumsky J, Striz I, Terl M, Vondracek J. Strategy aimed at reduction of sputum eosinophils decreases exacerbation rate in patients with asthma. Journal of International Medical Research 2006;34(2):129-39.

\section{Fleming 2012 \{published data only\}}

Fleming L, Wilson N, Regamey N, Bush A. Use of sputum eosinophil counts to guide management in children with severe asthma. Thorax 2012;67(11):1015-6.

Green 2002a \{published data only\}

Green RH, Brightling CE, McKenna S, Hargadon B, Parker D, Bradding P. Asthma exacerbations and sputum eosinophil counts: a randomised controlled trial. Lancet 2002;360(9347):1715-21.

\section{Jayaram 2006 \{published data only\}}

Chakir J, Loubaki L, Laviolette M, Milot J, Biardel S, Jayaram L, et al. Monitoring sputum eosinophils in mucosal inflammation and remodelling: a pilot study. European Respiratory Journal 2010;35(1):48-53.

D'silva L, Gafni A, Thabane L, Jayaram L, Hussack P, Hargreave F, et al. Cost analysis of monitoring asthma treatment using sputum cell counts. Canadian Respiratory Journal 2008;15(7):370-4.

Jayaram L, Pizzichini MM, Cook RJ, Boulet L-P, Lemière C, Pizzichini E, et al. Determining asthma treatment by monitoring sputum cell counts: effect on exacerbations. European Respiratory Journal 2006;27(3):483-94.

\section{Malerba 2015 \{published data only\}}

Malerba M, Radaeli A, Olivini A, Ragnoli B, Ricciardolo F, Montuschi P. The combined impact of exhaled nitric oxide and sputum eosinophils monitoring in asthma treatment: A prospective cohort study. Current Pharmaceutical Design 2015;21(32):4752-62.

\section{References to studies excluded from this review}

\section{Aldridge 2002 \{published data only\}}

Aldridge RE, Hancox RJ, Cowant JO, Frampton CM, Town GI, Taylor DR. Eosinophils and eosinophilic cationic protein in induced sputum and blood: effects of budesonide and terbutaline treatment. Annals of Allergy, Asthma \& Immunology 2002;89(5):492-7.
Almosawi 2008 \{published data only\}

* Almosawi TA, Al-Zubaidy TS, Howorth PH. Sputum eosinophil markers in monitoring asthmatic patients in United Arab Emirates. Saudi Medical Journal 2008;29(7):1061-4.

Foresi 2005 \{published data only\}

Foresi A, Mastropasqua B, Chetta A, D'Ippolito R, Testi R, Olivieri $D$, et al. Step-down compared to fixed-dose treatment with inhaled fluticasone propionate in asthma. Chest 2005;127(1):117-24.

\section{Gauvreau 2005 \{published data only\}}

Gauvreau GM, Watson RM, Postma DS, de Monchy GR, Deschesnes F, Boulet L. Effect of ciclesonide $40 \mu \mathrm{g}$ and $80 \mu \mathrm{g}$ on early and late asthmatic reactions, and sputum eosinophils after allergen challenge in patients with mild asthma. Journal of Allergy and Clinical Immunology. 2005; Vol. 115:S210.

\section{Giannini 2000 \{published data only\}}

Giannini D, Di Franco A, Cianchetti S, Bacci E, Dente FL, Vagaggini $B$, et al. Analysis of induced sputum before and after withdrawal of treatment with inhaled corticosteroids in asthmatic patients. Clinical and Experimental Allergy 2000;30(12):1777-84.

\section{Gibson 2001 \{published data only\}}

Gibson PG, Saltos N, Fakes K. Acute anti-inflammatory effects of inhaled budesonide in asthma: $A$ randomized controlled trial. American Journal of Respiratory and Critical Care Medicine 2001;163(1):32-6.

\section{Griese 2000 \{published data only\}}

Griese M, Koch M, Latzin P, Beck J. Asthma severity, recommended changes of inhaled therapy and exhaled nitric oxide in children: a prospective, blinded trial. European Journal of Medical Research 2000;5(8):334-40.

\section{Jatakanon 1997 \{published data only\}}

Jatakanon A, Kharitonov SA, Lim S, Chung KF, Barnes PJ. The effect of differing dosages of inhaled budesonide on asthmatic airway inflammation assessed by induced sputum. European Respiratory Journal 1997;10(Suppl 25):105s.

\section{Jatakanon 1998 \{published data only\}}

Jatakanon A, Lim S, Chung KF, Barnes PJ. An inhaled steroid improves markers of airway inflammation in patients with mild asthma. European Respiratory Journal 1998;12(5):1084-8.

\section{Leigh 2000 \{published data only\}}

Leigh R, Belda J, Parameswaran K, Hussack P, Efthimiadis A, Pizzichini MM, et al. Symptomatic patients with mild asthma with non-eosinophilic airway inflammation do not benefit from increased inhaled steroid treatment: a randomized controlled trial. American Journal of Respiratory and Critical Care Medicine 2000;161:A188.

\section{Lonnkvist 2001 \{published data only\}}

Lonnkvist K, Hellman C, Lundahl J, Hallden G, Hedlin G. Eosinophil markers in blood, serum, and urine for monitoring 
the clinical course in childhood asthma: Impact of budesonide treatment and withdrawal. Journal of Allergy and Clinical Immunology 2001;107(5 Suppl):812-7.

\section{Malerba 2008 \{published data only\}}

Malerba M, Ragnoli B, Radaeli A, Tantucci C. Usefulness of exhaled nitric oxide and sputum eosinophils in the long-term control of eosinophilic asthma. Chest 2008;134(4):733-9.

\section{McKinlay 2011a \{published data only\}}

McKinlay L, Williamson PA, Short PM, Fardon TC, Lipworth BJ. Proof of concept study to evaluate step-down therapy with inhaled corticosteroid alone or additive therapy on surrogate inflammatory markers in asthma. British Journal of Clinical Pharmacology 2011;71:128-31.

\section{McKinlay 2011b \{published data only\}}

McKinlay L, Jackson CM, Williamson PA, Fardon TC, Burns P, Clearie $\mathrm{K}$. Steroid titration against mannitol in mild to moderate asthma: The stamina community study. Journal of Allergy and Clinical Immunology 2011;127:2 Suppl 1.

\section{Meijer 2002 \{published data only\}}

Meijer RJ, Postma DS, Kauffman HF, Arends LR, Koeter GH, Kerstjens HA. Accuracy of eosinophils and eosinophil cationic protein to predict steroid improvement in asthma. Clinical and Experimental Allergy 2002;32(7):1096-103.

\section{Nocker 2000 \{published data only\}}

Nocker RE, Out TA, Weller FR, de Riemer MJ, Jansen HM, van der Zee JS. Induced sputum and bronchoalveolar lavage as tools for evaluating the effects of inhaled corticosteroids in patients with asthma. Journal of Laboratory and Clinical Medicine 2000;136(1):39-49.

\section{Prehn 2000 \{published data only\}}

Prehn A, Seger RA, Torresani T, Molinari L, Sennhauser FH. Evaluation of a clinical algorithm involving serum eosinophil cationic protein for guiding the anti-inflammatory treatment of bronchial asthma in childhood. Pediatric Allergy and Immunology 2000;11(2):87-94.

\section{Smith 2005 \{published data only\}}

Smith AD, Cowan JO, Brassett KP, Herbison GP, Taylor DR. Use of exhaled nitric oxide measurements to guide treatment in chronic asthma. New England Journal of Medicine 2005;352(21):2163-73.

\section{Sosa 2004 \{published data only\}}

Sosa IP, Nanulescu M. Induced sputum--means for detecting bronchial inflammation in children with atopic bronchial asthma and treatment monitoring [Sputa indusa--metoda de evidentiere a inflamatiei bronsice la copiii cu astm bronsic atopic si de monitorizare a tratamentului]. Pneumologia 2004;53(3):79-84.

\section{Van Rensen 1999 \{published data only\}}

Van Rensen ELJ, Evertse CE, van Schadewijk WAA, Zwinderman AH, Sterk PJ. Comparison of changes in exhaled nitric oxide, sputum eosinophils and histamine hyperresponsiveness in patients with mild asthma treated with inhaled steroids. American Journal of Respiratory and Critical Care Medicine 1998;157(3 Suppl):A608.

Wark 2003 \{published data only\}

Wark AB, Gibson PG. Clinical usefulness of inflammatory markers in asthma. American Journal of Respiratory Medicine 2003;2(1):11-9.

Wilson 2000 \{published data only\}

Wilson NM, Bridge P, Spanevello A, Silverman M. Induced sputum in children: feasibility, repeatability, and relation of findings to asthma severity. Thorax 2000;55(9):768-74.

Zacharasiewicz 2005 \{published data only\}

Zacharasiewicz A, Wilson N, Lex C, Erin EM, Li AM, Hansel T, et al. Clinical use of noninvasive measurements of airway inflammation in steroid reduction in children. American Journal of Respiratory and Critical Care Medicine 2005;171(10):1077-82.

Zubovic 2003 \{published data only\}

Zubovic I, Rozmanic V, Ahel V, Banac S. Assessment of treatment by measuring the level of eosinophylic cation protein (ECP) in the serum of children with asthma. Paediatria Croatica 2003;47(3):145-8.

\section{References to ongoing studies}

Pinot 2008 \{published and unpublished data\}

Pinot D, Nieves A, Lorec A, Botturi K, Cavailles A, Breen D, Vervloet $D$, Magnan A. A treatment regime based on induced sputum eosinophilia does not result in a reduction in exacerbations in refractory severe asthmatics. European Respiratory Society 18th Annual Congress; 2008 Oct 3-7; Berlin. 2008.

\section{Additional references}

Bacci 2002

Bacci E, Cianchetti S, Carnevali S, Bartoli ML, Dente FL, Di Franco A, et al. Induced sputum is a reproducible method to assess airway inflammation in asthma. Mediators of Inflammation 2002;11(5):293-8.

\section{BTS/SIGN 2016}

BTS/SIGN. British Thoracic Society/Scottish Intercollegiate Guidelines Network. British Guideline on the Management of Asthma: A national clinical guideline 2016. sign.ac.uk/pdf/ SIGN153.pdf (accessed 16 February 2017).

\section{Cates 2008 [Computer program]}

Cates C. Visual Rx. Online NNT Calculator. www.nntonline.net/: Dr Christopher Cates, 2008.

\section{Douwes 2002}

Douwes J, Gibson P, Pekkanen J, Pearce N. Non-eosinophilic asthma: importance and possible mechanisms. Thorax 2002;57:643-648. [DOI: http://dx.doi.org/10.1136/ thorax.57.7.643] 


\section{Elbourne 2002}

Elbourne DR, Altman DG, Higgins JPT, Curtin F, Worthington HV, Vail A. Meta-analyses involving cross-over trials: methodological issues. International Journal of Epidemiology 2002;31(1):140-9.

\section{GINA 2017}

Global Initiative for Asthma. Global Initiative for Asthma. Global Strategy for Asthma Management and Prevention, Global Initiative for Asthma (GINA) 2017. ginasthma.org/2017gina-report-global-strategy-for-asthma-management-andprevention/ (accessed 16 February 2017).

\section{Green 2002b}

Green RH, Brightling CE, Woltmann G, Parker D, Wardlow AJ, Pavord ID. Analysis of induced sputum in adults with asthma: identification of subgroup with isolated sputum neutrophilia and poor response to inhaled corticosteroids. Thorax 2002;57(10):875-9.

\section{Higgins 2011}

Higgins JPT, Green S (editors). Cochrane Handbook for Systematic Reviews of Interventions Version 5.1.0 [updated March 2011]. The Cochrane Collaboration, 2011. Available from handbook.cochrane.org.

\section{Karampitsakos 2016}

Karampitsakos T, Gourgoulianis KI. Asthma-COPD Overlap Syndrome (ACOS): Single disease entity or not? Could exhaled nitric oxide be a useful biomarker for the differentiation of ACOS, asthma and COPD?. Medical Hypotheses 2016;91:20-3. [DOI: 10.1016/j.mehy.2016.04.008]

\section{National Asthma Council 2014}

National Asthma Council Australia, Melbourne, 2014. Australian Asthma Handbook, Version 1.0. www.nationalasthma.org.au/ handbook (accessed 16 February 2017).

\section{Ohnishi 1998}

Ohnishi H, Maeda H, Nishimura Y, Yokoyama M. Benefits of induced sputum for the evaluation of therapeutic efficacy

\section{CHARACTERISTICS OF STUDIES}

Characteristics of included studies [ordered by study ID] in patients with bronchial asthma. Kobe Journal of Medical Sciences 1998;44(4):149-61.

\section{Review Manager 2014 [Computer program]}

The Nordic Cochrane Centre, The Cochrane Collaboration. Review Manager 5 (RevMan 5). Version 5.3. Copenhagen: The Nordic Cochrane Centre, The Cochrane Collaboration, 2014.

\section{Robinson 2017}

Robinson D, Humbert M, Buhl R, Cruz AA, Inoue H, Korom S, et al. Revisiting Type 2-high and Type 2-low airway inflammation in asthma: current knowledge and therapeutic implications. Clinical and Experimental Allergy 2017;47(2):161-75. [DOI: 10.1111/cea.12880]

\section{Seys 2017}

Seys SF. Role of sputum biomarkers in the management of asthma. Current Opinion in Pulmonary Medicine 2017;23(1):34-40. [DOI: 10.1097/MCP.0000000000000345]

\section{Wardlaw 2000}

Wardlaw AJ, Brightling C, Green R, Woltmann G, Pavord I. Eosinophils in asthma and other allergic diseases. British Medical Bulletin 2000;56(4):985-1003.

\section{Weiss 2001}

Weiss KB, Sullivan SD. The health economics of asthma and rhinitis. Assessing the economic impact. Journal of Allergy and Clinical Immunology 2001;107(1):3-8.

\section{References to other published versions of this review Petsky 2007}

Petsky HL, Kynaston JA, Turner C, Li AM, Cates CJ, Lasserson TJ, Chang AB. Tailored interventions based on sputum eosinophils versus clinical symptoms for asthma in children and adults. Cochrane Database of Systematic Reviews 2007, Issue 2. [DOI: 10.1002/14651858.CD005603.pub2]

* Indicates the major publication for the study

\section{Cao 2007}

Methods Randomised controlled, parallel-group trial comparing a strategy of minimising induced sputum eosinophil count with standard clinical guidelines.

Participants 
Cao 2007 (Continued)

Unclear as to how many patients withdrew after randomisation.

Interventions Participants had a 2-week run-in period and then were followed up for 6 months, with assessments attended at the end of months 2, 4 and 6 .

Sputum eosinophil group had treatment adjusted based on their sputum eosinophil count.

Standard clinical guidelines group had treatment adjusted based on asthma symptom score and use of

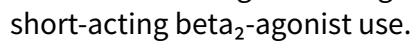

\begin{tabular}{ll}
\hline Outcomes & Primary outcome: total number of acute exacerbations \\
& Secondary outcomes: beta ${ }_{2}$-agonist use, symptom score, PEF variability, FEV $_{1} \%$, ICS use and sputum \\
eosinophil ratio.
\end{tabular}
eosinophil ratio.

\begin{tabular}{ll}
\hline Notes & Article published in Chinese and funded by the Capital Medical Development Foundation (No. \\
$2002-3004)$.
\end{tabular}
2002-3004).

\section{Risk of bias}

\begin{tabular}{lll}
\hline Bias & Authors' judgement & Support for judgement \\
\hline $\begin{array}{l}\text { Random sequence genera- } \\
\text { tion (selection bias) }\end{array}$ & Unclear risk & Random number table but unsure who conducted the generation. \\
\hline $\begin{array}{l}\text { Allocation concealment } \\
\text { (selection bias) }\end{array}$ & Unclear risk & No information about concealment was reported in the article. \\
\hline $\begin{array}{l}\text { Blinding of participants } \\
\text { and personnel (perfor- } \\
\text { mance bias) } \\
\text { All outcomes }\end{array}$ & Low risk & The investigators were blinded but unclear if the participants were blinded. \\
\hline $\begin{array}{l}\text { Blinding of outcome as- } \\
\text { sessment (detection bias) } \\
\text { All outcomes }\end{array}$ & Unclear risk & $\begin{array}{l}\text { The attending physician adjusted on sputum eosinophil count and blinded to } \\
\text { symptoms and pulmonary functions. }\end{array}$ \\
\hline $\begin{array}{l}\text { Incomplete outcome data } \\
\text { (attrition bias) } \\
\text { All outcomes }\end{array}$ & Unclear risk & Insufficient information in published article. \\
\hline $\begin{array}{l}\text { Selective reporting (re- } \\
\text { porting bias) }\end{array}$ & Unclear risk & Insufficient information in published article. \\
\hline \begin{tabular}{l} 
Other bias \\
\hline
\end{tabular} & Unclear risk & Unsure of the success in inducing sputum. \\
\hline
\end{tabular}

Chlumsky 2006

Methods An open, prospective, randomised, parallel-group trial comparing standard strategy of asthma severity
assessment (standard strategy) with a strategy based on reducing the number of sputum eosinophils (EOS strategy) over a period of 18 months.

Participants were stratified by dose of inhaled steroids, treatment with systemic steroids and add-on therapy with inhaled long-acting beta ${ }_{2}$-agonists and theophyllines.

Decisions in EOS strategy were made by an independent physician who was blinded to the participants' clinical data and telephoned the participants within one week after a study visit. 
Chlumsky 2006 (Continued)

There were 4 dropouts (all in standard strategy); 2 withdrew for protocol violation and 2 were lost to follow-up.

Participants were assessed every 3 months for 18 months.

Participants

55 participants were randomised. Standard strategy $N=21$, mean age 48 (SD 16), 6 males, 15 females. EOS strategy $N=30$, mean age 42 (SD 19), 13 males, 17 females.

Visiting an outpatients department.

Inclusion criteria: $\mathrm{FEV}_{1} 31 \%$ to $110 \%$ predicted, daily dose of inhaled corticosteroid 800 to $6400 \mathrm{mcg}$ budesonide or equivalent, diagnosis of asthma confirmed with bronchodilator response greater than $15 \%$ after $200 \mathrm{mcg}$ salbutamol and/or diurnal peak expiratory flow variation of $>20 \%$ on at least 4 of 14-day run-in period.

Exclusion criteria: current smokers and no upper respiratory tract infections within a month preceding the study.

Interventions

Participants were run in for 2 weeks and then attended outpatients in the morning at 3-monthly intervals for the 18 months.

Standard strategy arm: treatment decisions were based on morning PEF variation, frequency of daytime symptoms or short-acting beta ${ }_{2}$-agonists (SABA) use/week, frequency of night time symptoms or SABA/week.

EOS strategy: treatment decisions were based on the same as the standard strategy arm plus sputum eosinophils $\%$ of total cell count.

\begin{tabular}{ll} 
Outcomes & Primary outcome: rate of asthma exacerbations. \\
& Secondary outcomes: $\mathrm{FEV}_{1} ;$ post bronchodilator $\mathrm{FEV}_{1}$; and $\mathrm{FEV}_{1} /$ inspiratory vital capacity ratio. \\
\hline Notes & The study was funded by an Internal Grant Agency of the Ministry of Health of the Czech Republic (Grant \\
& No. $5866 / 3)$
\end{tabular}

\section{Risk of bias}

\begin{tabular}{|c|c|c|}
\hline Bias & Authors' judgement & Support for judgement \\
\hline $\begin{array}{l}\text { Random sequence genera- } \\
\text { tion (selection bias) }\end{array}$ & Low risk & Independent investigator using a computer program. \\
\hline $\begin{array}{l}\text { Allocation concealment } \\
\text { (selection bias) }\end{array}$ & Unclear risk & Insufficient information of concealment in published article. \\
\hline $\begin{array}{l}\text { Blinding of participants } \\
\text { and personnel (perfor- } \\
\text { mance bias) } \\
\text { All outcomes }\end{array}$ & High risk & Open label, therefore participants and investigators were not blinded. \\
\hline $\begin{array}{l}\text { Blinding of outcome as- } \\
\text { sessment (detection bias) } \\
\text { All outcomes }\end{array}$ & Unclear risk & $\begin{array}{l}\text { An independent physician who was blinded to the participants' clinical infor- } \\
\text { mation made decisions for the EOS strategy; however for the standard strate- } \\
\text { gy the dose was adjusted by the investigators. }\end{array}$ \\
\hline $\begin{array}{l}\text { Incomplete outcome data } \\
\text { (attrition bias) } \\
\text { All outcomes }\end{array}$ & Unclear risk & Insufficient information provided in published article. \\
\hline $\begin{array}{l}\text { Selective reporting (re- } \\
\text { porting bias) }\end{array}$ & Unclear risk & Insufficient information provided in published article. \\
\hline Other bias & Unclear risk & Nil information provided on success of inducing sputum. \\
\hline
\end{tabular}

Tailored interventions based on sputum eosinophils versus clinical symptoms for asthma in children and adults (Review) 
Fleming 2012

Methods
Randomised, double-blind, parallel study comparing asthma management based on the differential sputum eosinophil count with conventional management.

Neither the physicians nor the participants were aware of which group they were randomised to.

There were 6 dropouts including 1 with uncontrolled asthma during follow-up.

Study duration was 12 months with 5 study visits.
55 children randomised from 65 invited to participate. Inflammatory management group $n=27$ : median age 13.4 (range 11 to 15.8 ), 16 males, 11 females. Symptom management group $n=28$ : median age 12.6 (range 10.2 to 14.7 ), 13 males, 15 females.

Attending outpatient clinic at the Royal Brompton Hospital, UK.

Inclusion criteria: children with severe asthma diagnosed by a paediatric respiratory physician and requiring steps 4 or 5 of the British Thoracic Society/Scottish Intercollegiate Guidelines Network (BTS/ SIGN) guidelines ( $\geq 500 \mathrm{mcg}$ fluticasone propionate/day or equivalent plus a long-acting beta agonist plus a trial of leukotriene receptor antagonist).

Exclusion criteria: currently prescribed an immunomodulatory steroid-sparing agent or a continuous infusion of subcutaneous terbutaline, or had received intramuscular triamcinolone in the previous 3 months or had another significant chronic respiratory or medical condition.
Interventions
Outpatient visits were at baseline, months $3,6,9,12$

Symptom management group: treatment decisions made on the number of major exacerbations (defined as those needing treatment with high-dose oral corticosteroids ( $>20 \mathrm{mg} /$ day) for $\geq 2$ days in the

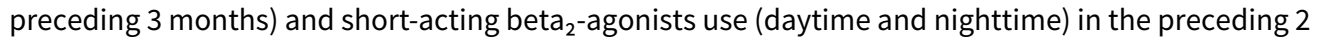
weeks.

Inflammatory management group: treatment decisions were based on the differential sputum eosinophil count (performed by an investigator blinded to the identity, clinical status and randomisation group of the participant) to keep level below $2.5 \%$.

Outcomes Primary outcome: rate of major exacerbations and asthma control as assessed by symptom-free days and SABA use.

Secondary outcome: daily dose of ICS prescribed over the course of the study.

\section{Risk of bias}

Bias Authors' judgement Support for judgement

\begin{tabular}{lll}
\hline $\begin{array}{l}\text { Random sequence genera- } \\
\text { tion (selection bias) }\end{array}$ & Low risk & Generated by an independent statistician using random numbers. \\
\hline $\begin{array}{l}\text { Allocation concealment } \\
\text { (selection bias) }\end{array}$ & Unclear risk & Insufficient information of concealment in published article. \\
\hline $\begin{array}{l}\text { Blinding of participants } \\
\begin{array}{l}\text { and personnel (perfor- } \\
\text { mance bias) }\end{array}\end{array}$ & Low risk & Double blinded, i.e. physician and participant (child and parent). \\
$\begin{array}{l}\text { All outcomes } \\
\end{array}$ & \\
\hline
\end{tabular}

\begin{tabular}{|c|c|c|}
\hline $\begin{array}{l}\text { Blinding of outcome as- } \\
\text { sessment (detection bias) }\end{array}$ & Low risk & $\begin{array}{l}\text { The investigator conducting the sputum analysis was blinded to the partici- } \\
\text { pant's identity, clinical status and randomisation group. }\end{array}$ \\
\hline
\end{tabular}

Tailored interventions based on sputum eosinophils versus clinical symptoms for asthma in children and adults (Review) 
Fleming 2012 (Continued)

All outcomes

Incomplete outcome data Low risk Analysis completed on intention-to-treat basis.
(attrition bias)

(attrition bias)

All outcomes

Selective reporting (re- Low risk $\quad$ All outcomes reported in the text.
porting bias)

porting bias)

Other bias Unclear risk

Sputum induction was successful on 174 (85\%) occasions; 152 of these had sputum differential cell count obtained. FeNO was used to determine management on 27 occasions in inflammatory management group. Society (BTS group) asthma guidelines or by normalising sputum eosinophil count (Sputum management group).

Participants were stratified by number of oral corticosteroids used in the previous 12 months, the baseline-induced sputum eosinophil count and baseline methacholine PC20.

Neither the physicians nor the participants were aware of which group they were randomised to or the treatment protocol. At completion of the study each participant was asked to guess which group they were in.

There were 14 dropouts, 8 during run-in and 6 during follow-up.

The study ran for 12 months and the participants were assessed 9 times.

Participants adults randomised from 82 recruited participants. Sputum management group $\mathrm{n}=37$ : median age
50, range 19 to 73,19 males, 18 females.
BTS management group $\mathrm{n}=37$ : median age 47 , range 20 to 75,21 males, 16 females.
Attending one of 3 specialists clinics at Glenfield Hospital, Leicester, UK.
Inclusion: diagnosis of asthma and needed hospital follow-up.
Exclusion: current smokers, had a history of smoking more than 15 packs/year, clinically important co-
morbidity, poor compliance, inadequately controlled aggravating factors e.g. rhinitis or GOR, had se-
vere asthma exacerbation within 4 weeks of entry.

Interventions

Outpatient visits were at baseline, month 1, 2, 3, 4, 6, 8, 10, 12 .

BTS management group: treatment decisions were based on traditional assessments of symptoms, peak expiratory flow and use of beta ${ }_{2}$-agonists.

Sputum management group: anti-inflammatory treatment was based on maintenance of sputum eosinophil count below $3 \%$ with a minimum dose of anti-inflammatory treatment.

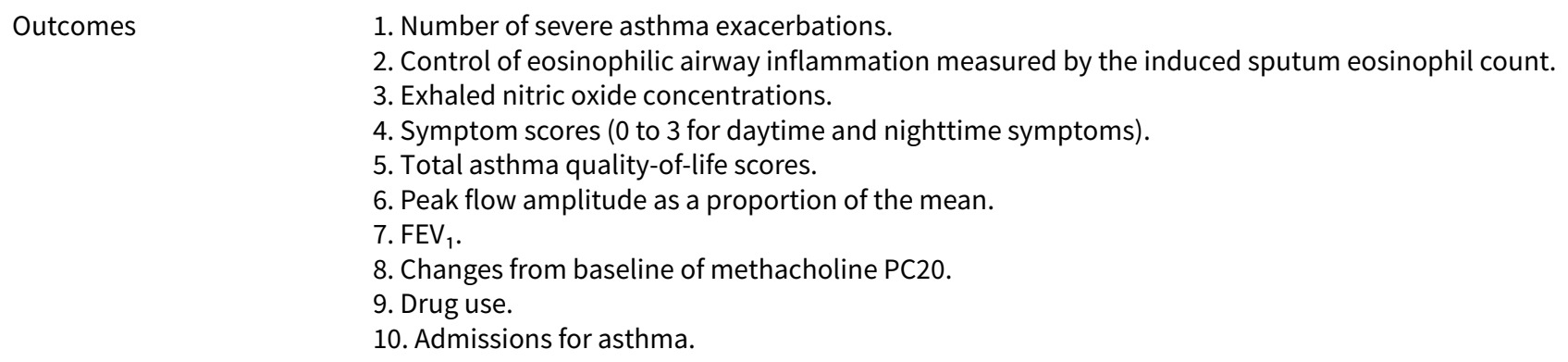


Green 2002a (Continued)

Risk of bias

\begin{tabular}{|c|c|c|}
\hline Bias & Authors' judgement & Support for judgement \\
\hline $\begin{array}{l}\text { Random sequence genera- } \\
\text { tion (selection bias) }\end{array}$ & Low risk & Randomised by independent individual with method of minimisation. \\
\hline $\begin{array}{l}\text { Allocation concealment } \\
\text { (selection bias) }\end{array}$ & Unclear risk & Insufficient information in published article. \\
\hline $\begin{array}{l}\text { Blinding of participants } \\
\text { and personnel (perfor- } \\
\text { mance bias) } \\
\text { All outcomes }\end{array}$ & Low risk & Double blind, i.e. physician and participants. \\
\hline $\begin{array}{l}\text { Blinding of outcome as- } \\
\text { sessment (detection bias) } \\
\text { All outcomes }\end{array}$ & Low risk & $\begin{array}{l}\text { Management decisions were made by an independent individual who was un- } \\
\text { aware of clinical characteristics of the participant, and who recorded separate } \\
\text { treatment plans to be followed depending on whether the participant's asth- } \\
\text { ma was controlled well or poorly. }\end{array}$ \\
\hline $\begin{array}{l}\text { Incomplete outcome data } \\
\text { (attrition bias) } \\
\text { All outcomes }\end{array}$ & Low risk & Analysis by intention to treat and extrapolated for the 12 -month period. \\
\hline $\begin{array}{l}\text { Selective reporting (re- } \\
\text { porting bias) }\end{array}$ & Low risk & All outcomes reported in the published article. \\
\hline Other bias & Unclear risk & Sputum induction successful in 552 of 632 attempts (87\%). \\
\hline
\end{tabular}

Jayaram 2006

Methods

Randomised, double-blind, parallel-group, effectiveness study. It was a multicentre study over a 2-year period.

Stratified by duration of the asthmatic symptoms ( $\leq 20$ years or $>20$ years), ICS dose (equivalent to fluticasone $\leq 500$ or $>500 \mathrm{mcg} /$ day) and $\mathrm{FEV}_{1}(\leq 70 \%$ or $>70 \%$ predicted).

Participants blinded to sputum cell counts. Physicians blinded to sputum cell count in clinical strategy group.

Dropouts: 15 dropouts including 5 who were excluded due to protocol violations by investigator.

Participants
Clinical strategy group $\mathrm{n}=52$; mean age 43.5 (SD 13.9), 15 males, 37 females.
Sputum strategy group $\mathrm{n}=50$; mean age 46 (SD 13.8), 15 males, 35 females.
Attending 1 of 3 Canadian or 1 Brazilian chest clinic.
Inclusion criteria: symptoms of asthma for a minimum of a year.
Exclusion criteria: not mentioned.

\section{Interventions Clinical strategy: guided by symptoms and strategy.}

Sputum strategy: dose of inhaled steroid was guided solely by induced sputum eosinophils to keep < $2 \%$. Spirometry and symptoms were used to identify clinical control, exacerbations and other treatment.

1. Relative risk reduction for the first exacerbation.
2. The length of time without exacerbations.
3. Type and severity of exacerbations.

Tailored interventions based on sputum eosinophils versus clinical symptoms for asthma in children and adults (Review) 
4. The usefulness of monitoring sputum cell counts in relation to the overall severity of asthma. Defined by the minimum dose of inhaled steroid to maintain control.

5. The cumulative dose of inhaled steroid needed in Phase 2 adjusted for its duration.

Notes The study was supported by a Canadian Institutes of Health Research Clinical Trials Grant.

\section{Risk of bias}

\begin{tabular}{lll}
\hline Bias & Authors' judgement & Support for judgement \\
\hline $\begin{array}{l}\text { Random sequence genera- } \\
\text { tion (selection bias) }\end{array}$ & Low risk & Randomised off-site in blocks of 4. \\
\hline $\begin{array}{l}\text { Allocation concealment } \\
\text { (selection bias) }\end{array}$ & Unclear risk & Information not available in published article. \\
\hline
\end{tabular}

Blinding of participants Low risk Physician and participants blinded.

and personnel (perfor-

mance bias)

All outcomes

\begin{tabular}{lll}
\hline $\begin{array}{l}\text { Blinding of outcome as- } \\
\text { sessment (detection bias) }\end{array}$ & Unclear risk & In the control strategy the investigators were blinded to the sputum cell \\
counts but no blinding for outcomes in the sputum strategy.
\end{tabular}

All outcomes

Incomplete outcome data Low risk All outcomes reported as planned.
(attrition bias)

(attrition bias)

All outcomes

Selective reporting (re- Low risk Adjudicator researcher used, blinded to treatment arms.
porting bias)

Other bias Unclear risk Sputum induction successful in $81 \%$ of attempts.
cal score.

Study duration was 24 months with 6 outpatient visits, at month 0, 3, 6, 12, 18 and 24 .

The study personnel assessing outcome measures were blinded. The participants were not blinded.

Participants 28 adults with confirmed diagnosis of asthma (confirmed by positive response to methacholine chal-
lenge) randomised from 40 screened.

Clinical strategy: $n=14$; mean age 46.7 years (SD 30.1), 6 males, 8 females.

Sputum strategy: $\mathrm{n}=14$; mean age 45.2 years (SD 31.2), 5 males, 9 females.

Inclusion criteria: aged 18 to 70 years with mild to moderate asthma, sputum eosinophil cell counts > $3 \%$. All were on maintenance ICS with or without LABA.

Exclusion criteria: previous respiratory tract infection in the previous 6 weeks, oral corticosteroids in the previous 4 weeks, co-morbidities of hepatic, cardiovascular, neurologic, respiratory diseases 
Malerba 2015 (Continued)

such as bronchiectasis, cystic fibrosis, COPD or respiratory failure. Participants could not be on angiotensin-converting enzyme inhibitors or beta-blockers or anti-depressants.

\begin{tabular}{|c|c|}
\hline \multirow[t]{2}{*}{ Interventions } & $\begin{array}{l}\text { Clinical strategy: treatment was adjusted based on symptom score, use of beta }{ }_{2} \text {-agonists and night } \\
\text { symptoms. }\end{array}$ \\
\hline & 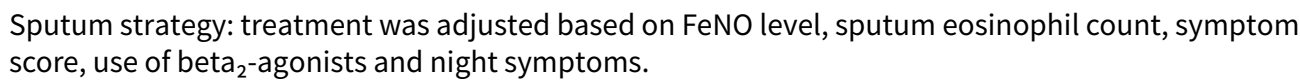 \\
\hline
\end{tabular}

\begin{tabular}{ll}
\hline Outcomes & Primary outcome: asthma exacerbations combined with changes in symptom score at end of study. \\
& Secondary outcomes: mean values of $\mathrm{PD}_{20}, \mathrm{FEV}_{1}, \mathrm{FEV}_{1} / \mathrm{FVC}$ ratio, FeNO, sputum eosinophil cell counts \\
and variations in ICS dose.
\end{tabular}

Notes Study funded by the University of Brescia. Authors state they have no conflicts of interest to disclose.

\section{Risk of bias}

\begin{tabular}{|c|c|c|}
\hline Bias & Authors' judgement & Support for judgement \\
\hline $\begin{array}{l}\text { Random sequence genera- } \\
\text { tion (selection bias) }\end{array}$ & Unclear risk & $\begin{array}{l}\text { "Randomisation schedule" used to assign participants but unclear on the } \\
\text { method. Block randomisation with 1:1 allocation. }\end{array}$ \\
\hline $\begin{array}{l}\text { Allocation concealment } \\
\text { (selection bias) }\end{array}$ & Unclear risk & $\begin{array}{l}\text { "Principal investigator enrolled participants and assigned to study groups" } \\
\text { with no description of allocation. }\end{array}$ \\
\hline $\begin{array}{l}\text { Blinding of participants } \\
\text { and personnel (perfor- } \\
\text { mance bias) } \\
\text { All outcomes }\end{array}$ & Unclear risk & $\begin{array}{l}\text { States single blind with the "person assessing outcome measures were blind- } \\
\text { ed", participants were not blinded. }\end{array}$ \\
\hline $\begin{array}{l}\text { Blinding of outcome as- } \\
\text { sessment (detection bias) } \\
\text { All outcomes }\end{array}$ & Unclear risk & $\begin{array}{l}\text { States single blind with the "person assessing outcome measures were blind- } \\
\text { ed" but unclear who did the eosinophil counts. }\end{array}$ \\
\hline $\begin{array}{l}\text { Incomplete outcome data } \\
\text { (attrition bias) } \\
\text { All outcomes }\end{array}$ & Low risk & $\begin{array}{l}\text { All randomised participants finished the study and authors report "no missing } \\
\text { data". }\end{array}$ \\
\hline $\begin{array}{l}\text { Selective reporting (re- } \\
\text { porting bias) }\end{array}$ & Low risk & All outcome measures were reported in published paper. \\
\hline Other bias & Low risk & Nil noted. \\
\hline
\end{tabular}

BTS: British Thoracic Society; FeNO: fractional exhaled nitric oxide; FEV 1 : forced expiratory volume in 1 second; GOR: gastro-oesophageal reflux; ICS: inhaled corticosteroids; N: number; PEF: peak expiratory flow; SABA: short-acting beta-agonist; SD: standard deviation

Characteristics of excluded studies [ordered by study ID]

\begin{tabular}{ll}
\hline Study & Reason for exclusion \\
\hline Aldridge 2002 & $\begin{array}{l}\text { Randomised, placebo-controlled, cross-over study of terbutaline and budesonide, comparing the } \\
\text { changes in eosinophil counts and ECP in induced sputum and blood. Excluded as treatment was } \\
\text { not adjusted according to sputum eosinophil counts. }\end{array}$ \\
\hline
\end{tabular}




\begin{tabular}{ll}
\hline Study & Reason for exclusion \\
\hline Almosawi 2008 & $\begin{array}{l}\text { Non-randomised, nor treatment based on sputum eosinophil counts. Observational study to deter- } \\
\text { mine the relationship between sputum eosinophil markers and asthma severity and prognosis in } \\
\text { atopic and non-atopic patients in United Arab Emirates. }\end{array}$ \\
\hline
\end{tabular}

Foresi 2005

Randomised, double-blind, parallel study treating one group with fluticasone propionate 1000 $\mathrm{mcg} /$ day and then reducing to $200 \mathrm{mcg} /$ day in comparison to a fixed dose of fluticasone $200 \mathrm{mcg} /$ day in the control of bronchial hyper-responsiveness to methacholine and eosinophilic inflammation. Excluded as treatment was not adjusted using sputum eosinophils.

Gauvreau 2005

Excluded as treatment was not adjusted according to sputum eosinophils. Randomised, double-blind, cross-over study of ciclesonide versus placebo after allergen challenge.

\section{Giannini 2000}

Excluded as treatment not adjusted according to sputum eosinophil counts. Randomised, double-blind, placebo-controlled study of beclomethasone dipropionate versus placebo.

\section{Gibson 2001}

Randomised, double-blind, placebo-controlled, cross-over trial of single dose of budesonide 2400 mcg versus placebo and effect on sputum eosinophils and mast cells in adults with asthma. Excluded as treatment was not based on sputum eosinophil count.

\section{Griese 2000} Non-RCT nor treatment based on sputum eosinophil count. Prospective study to assess exhaled nitric oxide in comparison to clinical symptoms, treatment adjusted using clinical symptoms.

\begin{tabular}{ll}
\hline Jatakanon 1997 & $\begin{array}{l}\text { Randomised, double-blind, cross-over study of budesonide versus placebo. Excluded as treatment } \\
\text { not based on eosinophil count. }\end{array}$ \\
\hline Jatakanon 1998 & $\begin{array}{l}\text { Excluded as treatment not based on sputum eosinophils. Randomised into two double-blind, } \\
\text { placebo-controlled studies (1 was parallel study involving } 3 \text { groups receiving either budesonide } \\
100 \mathrm{mcg} / \text { day, budesonide } 400 \mathrm{mcg} / \text { day or placebo; the second was a cross-over randomised to re- } \\
\text { ceive budesonide } 1600 \mathrm{mcg} \text { or placebo). }\end{array}$ \\
\hline Leigh 2000 & $\begin{array}{l}\text { Excluded as treatment not adjusted based on sputum eosinophils. RCT of budesonide versus } \\
\text { placebo in patients with mild to moderate asthma who had non-eosinophilic airway inflammation. }\end{array}$ \\
\hline Lonnkvist 2001 & $\begin{array}{l}\text { Treatment not adjusted according to sputum eosinophil. RCT of budesonide versus placebo in chil- } \\
\text { dren with mild to moderate asthma. Investigated the effect of withdrawing inhaled budesonide } \\
\text { on eosinophil count in blood and eosinophil proteins in serum and urine, and the relationship be- } \\
\text { tween these markers and symptoms of asthma. }\end{array}$
\end{tabular}

\begin{tabular}{ll}
\hline Malerba 2008 & Excluded as non-RCT but prospective observational study. Anti-inflammatory therapy was adjusted \\
according to FeNO and sputum eosinophil values.
\end{tabular}

McKinlay 2011a

Treatment not adjusting according to sputum eosinophil counts. RCT to evaluate the usefulness of inflammatory surrogates (adenosine monophosphate) in determining step-down therapy in asthma.

\begin{tabular}{ll}
\hline McKinlay 2011b & $\begin{array}{l}\text { Treatment not adjusted according to sputum eosinophil counts. RCT where patients were treated } \\
\text { according to BTS guidelines or mannitol challenge. }\end{array}$ \\
\hline Meijer 2002 & $\begin{array}{l}\text { Excluded as treatment not adjusted according to sputum eosinophils. Randomised to either pred- } \\
\text { nisolone } 30 \mathrm{mg} / \text { day, fluticasone propionate } 2000 \mathrm{mcg} / \text { day or fluticasone propionate } 500 \mathrm{mcg} / \mathrm{day} \\
\text { for } 2 \text { weeks. }\end{array}$ \\
\hline Nocker 2000 & $\begin{array}{l}\text { Randomised parallel group study to evaluate the usefulness of induced sputum as an alternative to } \\
\text { bronchoalveolar lavage. Excluded as treatment not adjusted according to sputum eosinophils. }\end{array}$ \\
\hline
\end{tabular}




\begin{tabular}{ll}
\hline Study & Reason for exclusion \\
\hline Prehn 2000 & $\begin{array}{l}\text { Excluded as randomised to serum eosinophil cationic protein levels. A pilot study of } 21 \text { asthmat- } \\
\text { ic children, allocated to receive budesonide } 200 \mathrm{mcg} \text { twice daily if ECP between } 15 \text { to } 30 \mathrm{mcg} / \mathrm{L} \text { or } \\
\text { budesonide } 400 \mathrm{mcg} \text { twice daily if } \mathrm{ECP}>30 \mathrm{mcg} / \mathrm{L} .\end{array}$
\end{tabular}

Smith 2005 Randomised, single-blind, placebo-controlled trial adjusting corticosteroids based on exhaled nitric oxide versus conventional guidelines. Excluded as treatment not based on sputum eosinophil count.

Sosa $2004 \quad$ Non-RCT, literature review about sputum induction to explore airway inflammation in asthma.

Van Rensen $1999 \quad$ Excluded as treatment not based on sputum eosinophil count. Randomised, double-blind, placebo-controlled parallel study to compare the changes in non-invasive markers (airway hyper-responsiveness, sputum eosinophils and exhaled nitric oxide) after treatment with inhaled glucocorticosteroids.

\section{Wark 2003}

Non-randomised nor treatment adjusted based on sputum eosinophil count. Review article looking at the techniques of sputum induction, exhaled gas measurements and blood or serum measures as noninvasive measures of eosinophilic inflammation.

Wilson 2000

Non-RCT. Cross-sectional study of children to determine the feasibility of sputum induction, repeatability of sputum eosinophil counts and the correlation to asthma symptoms.

Non-RCT. Prospective, observational study in children using non-invasive measures (exhaled nitric oxide, induced sputum and exhaled breath condensate) to monitor airway inflammation to result in optimal treatment.

Zubovic 2003

RCT using serum eosinophil cationic protein (ECP). Excluded as not using sputum eosinophil. One group was treated with disodium cromoglycate and the other corticosteroid flunisolide to assess the success of anti-inflammatory treatment by measuring the level of ECP and FEV ${ }_{1}$.

\section{Characteristics of ongoing studies [ordered by study ID]}

\section{Pinot 2008}

Trial name or title

\section{Methods}

\section{Participants}

Interventions

\section{Outcomes}

\section{Starting date}

Contact information 
DATA AND ANALYSES

Comparison 1. Asthma treatment tailored on sputum esoinophils versus symptoms

\begin{tabular}{|c|c|c|c|c|}
\hline Outcome or subgroup title & No. of studies & $\begin{array}{l}\text { No. of partici- } \\
\text { pants }\end{array}$ & Statistical method & Effect size \\
\hline 1 Occurrence of any exacerbation & 4 & 269 & Rate Ratio (Random, 95\% Cl) & $0.57[0.38,0.86]$ \\
\hline 1.1 Adults & 3 & 215 & Rate Ratio (Random, 95\% CI) & $0.45[0.24,0.86]$ \\
\hline 1.2 Children & 1 & 54 & Rate Ratio (Random, 95\% Cl) & $0.75[0.54,1.04]$ \\
\hline $\begin{array}{l}2 \text { Number of participants who had } \\
\text { one or more exacerbations over } \\
\text { the study period }\end{array}$ & 4 & 269 & $\begin{array}{l}\text { Odds Ratio (M-H, Fixed, 95\% } \\
\mathrm{Cl})\end{array}$ & $0.36[0.21,0.62]$ \\
\hline 2.1 Adult & 3 & 215 & $\begin{array}{l}\text { Odds Ratio (M-H, Fixed, 95\% } \\
\mathrm{Cl} \text { ) }\end{array}$ & $0.36[0.20,0.64]$ \\
\hline 2.2 Children & 1 & 54 & $\begin{array}{l}\text { Odds Ratio (M-H, Fixed, 95\% } \\
\mathrm{Cl})\end{array}$ & $0.39[0.09,1.71]$ \\
\hline $\begin{array}{l}3 \text { Number of participants with ex- } \\
\text { acerbations regarding hospitalisa- } \\
\text { tions over the study period }\end{array}$ & 4 & 269 & $\begin{array}{l}\text { Odds Ratio (M-H, Fixed, 95\% } \\
\mathrm{Cl})\end{array}$ & $0.28[0.09,0.84]$ \\
\hline 3.1 Adult & 3 & 215 & $\begin{array}{l}\text { Odds Ratio (M-H, Fixed, 95\% } \\
\mathrm{Cl} \text { ) }\end{array}$ & $0.14[0.02,1.25]$ \\
\hline 3.2 Children & 1 & 54 & $\begin{array}{l}\text { Odds Ratio (M-H, Fixed, 95\% } \\
\mathrm{Cl})\end{array}$ & $0.38[0.10,1.45]$ \\
\hline $\begin{array}{l}4 \text { Number of severe exacerbations } \\
\text { requiring oral corticosteroids }\end{array}$ & 1 & & Rate Ratio (Fixed, 95\% Cl) & Totals not selected \\
\hline $\begin{array}{l}5 \text { MIld exacerbations over study } \\
\text { period }\end{array}$ & 2 & 150 & Rate Ratio (Fixed, 95\% Cl) & $0.82[0.67,1.00]$ \\
\hline $\begin{array}{l}6 \text { Eosinophilic v Noneosinophilic } \\
\text { exacerbations }\end{array}$ & 1 & & Risk Ratio (Fixed, 95\% Cl) & Subtotals only \\
\hline 6.1 Eosinophilic Exacerbations & 1 & 2 & Risk Ratio (Fixed, 95\% Cl) & $0.28[0.10,0.76]$ \\
\hline 6.2 Noneosinophilic Exacerbations & 1 & 2 & Risk Ratio (Fixed, 95\% Cl) & $1.07[0.62,1.85]$ \\
\hline $\begin{array}{l}7 \text { Exacerbations subgrouped by } \\
\text { asthma severity: Mild vs Severe }\end{array}$ & 1 & & Rate Ratio (Fixed, 95\% CI) & Subtotals only \\
\hline 7.1 Very mild to mild asthma & 1 & 2 & Rate Ratio (Fixed, 95\% CI) & $1.34[0.52,3.43]$ \\
\hline 7.2 Moderate to severe asthma & 1 & 2 & Rate Ratio (Fixed, 95\% CI) & $0.63[0.38,1.04]$ \\
\hline $\begin{array}{l}8 \text { Exacerbations subgrouped by } \\
\text { asthma severity: Use of LABA }\end{array}$ & 1 & & Rate Ratio (Fixed, 95\% Cl) & Subtotals only \\
\hline 8.1 On LABA & 1 & 2 & Rate Ratio (Fixed, 95\% Cl) & $0.53[0.25,1.14]$ \\
\hline
\end{tabular}




\begin{tabular}{|c|c|c|c|c|}
\hline Outcome or subgroup title & No. of studies & $\begin{array}{l}\text { No. of partici- } \\
\text { pants }\end{array}$ & Statistical method & Effect size \\
\hline 8.2 Not on LABA & 1 & 2 & Rate Ratio (Fixed, 95\% Cl) & $1.05[0.62,1.78]$ \\
\hline $\begin{array}{l}9 \text { Mean dose of inhaled corticos- } \\
\text { teroids per person per day (Bud } \\
\text { equiv) }\end{array}$ & 5 & 316 & $\begin{array}{l}\text { Mean Difference (Fixed, 95\% } \\
\mathrm{CI} \text { ) }\end{array}$ & $\begin{array}{l}12.56[-127.92 \\
153.04]\end{array}$ \\
\hline 9.1 Adults & 4 & 262 & $\begin{array}{l}\text { Mean Difference (Fixed, 95\% } \\
\mathrm{Cl} \text { ) }\end{array}$ & $0.67[-154.39,155.73]$ \\
\hline 9.2 Children & 1 & 54 & $\begin{array}{l}\text { Mean Difference (Fixed, 95\% } \\
\mathrm{Cl} \text { ) }\end{array}$ & $67.0[-264.81,398.81]$ \\
\hline $\begin{array}{l}10 \text { Mean dose of oral corticos- } \\
\text { teroids per person per day }\end{array}$ & 1 & & $\begin{array}{l}\text { Mean Difference (Fixed, 95\% } \\
\mathrm{Cl} \text { ) }\end{array}$ & Totals not selected \\
\hline 11 Yearly cost per person (USD) & 1 & & $\begin{array}{l}\text { Mean Difference (IV, Fixed, } \\
95 \% \mathrm{CI} \text { ) }\end{array}$ & Totals not selected \\
\hline
\end{tabular}

Analysis 1.1. Comparison 1 Asthma treatment tailored on sputum esoinophils versus symptoms, Outcome 1 Occurrence of any exacerbation.

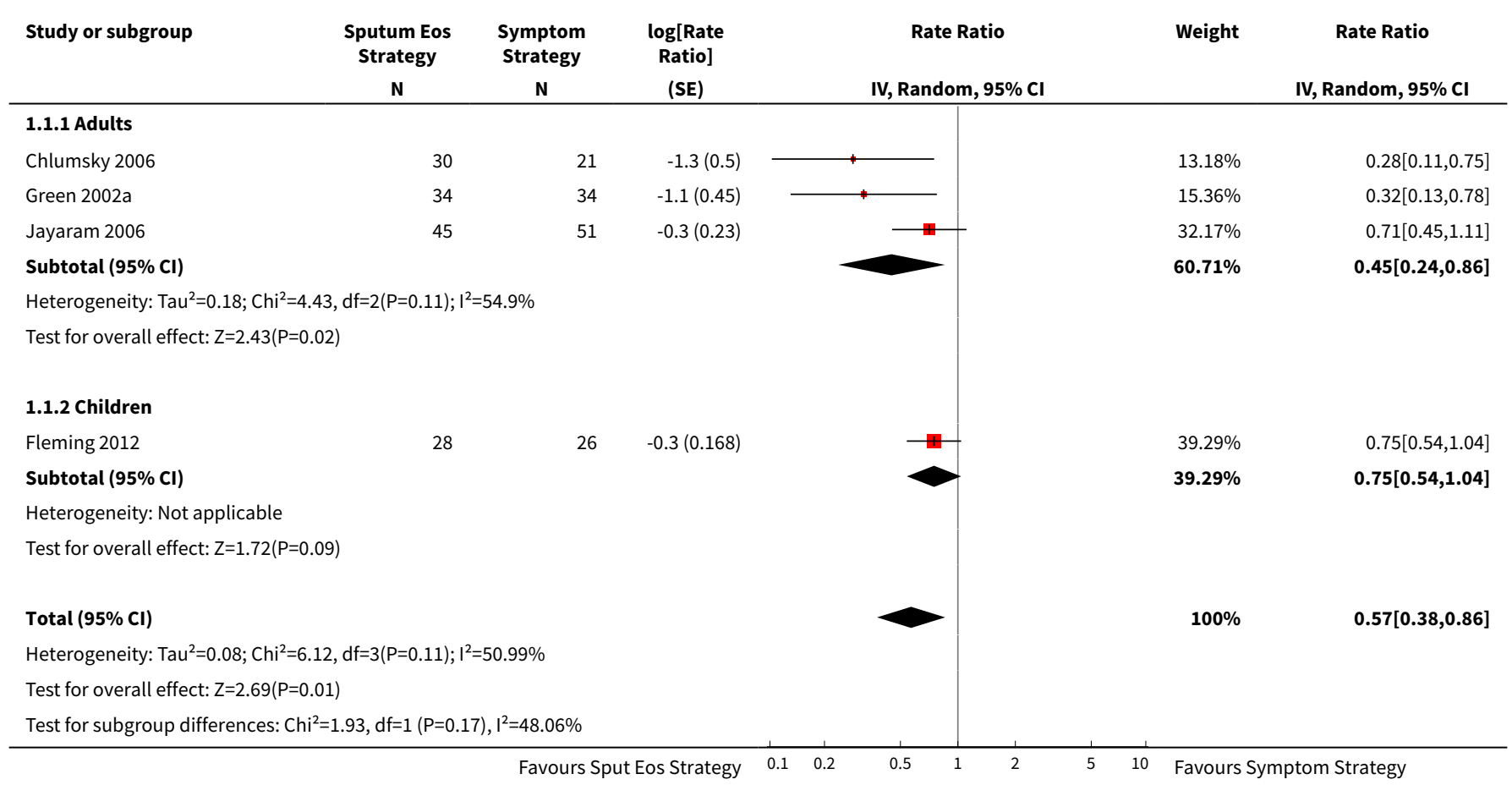


Analysis 1.2. Comparison 1 Asthma treatment tailored on sputum esoinophils versus symptoms, Outcome 2 Number of participants who had one or more exacerbations over the study period.

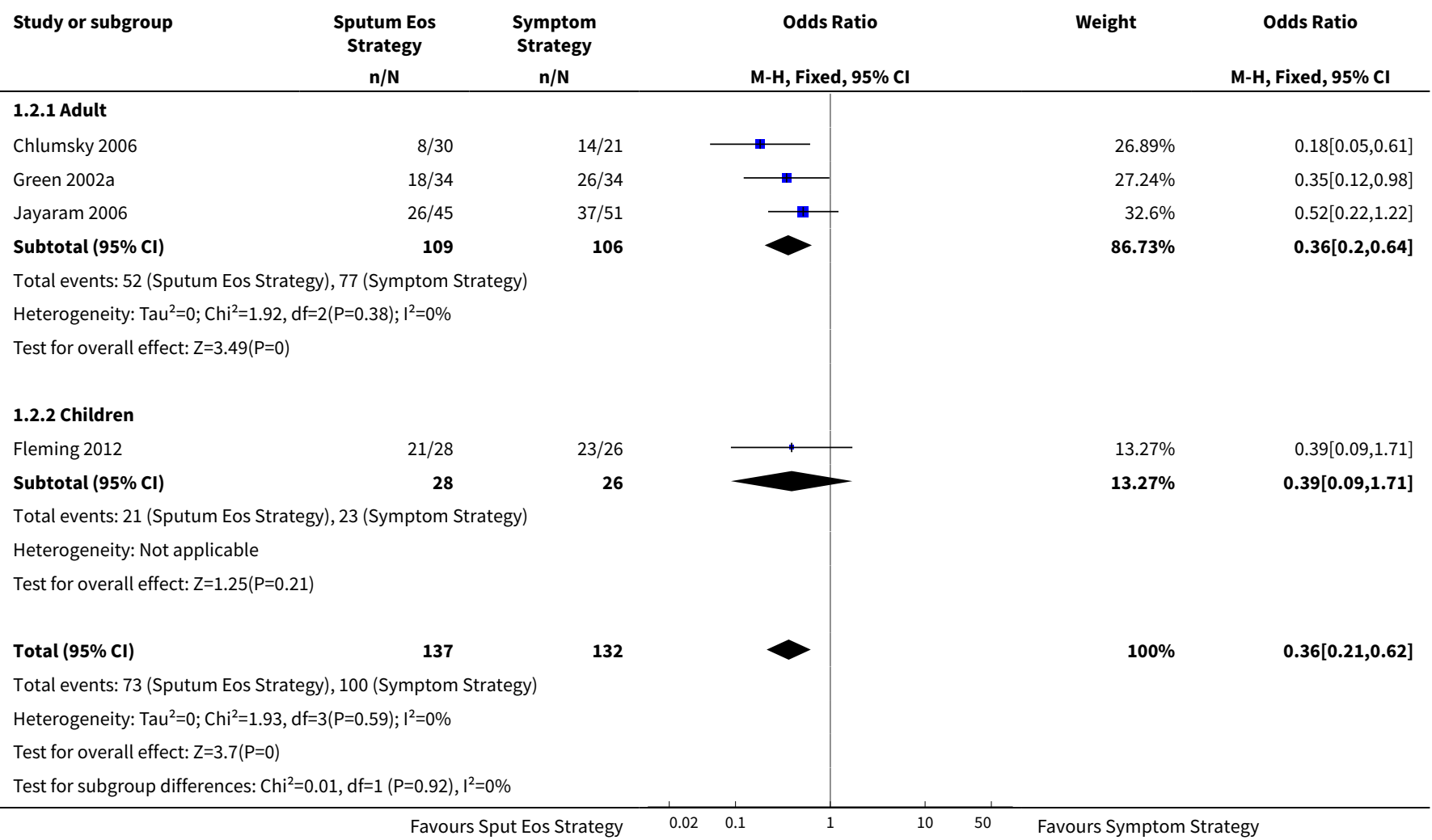

Analysis 1.3. Comparison 1 Asthma treatment tailored on sputum esoinophils versus symptoms, Outcome 3 Number of participants with exacerbations regarding hospitalisations over the study period.

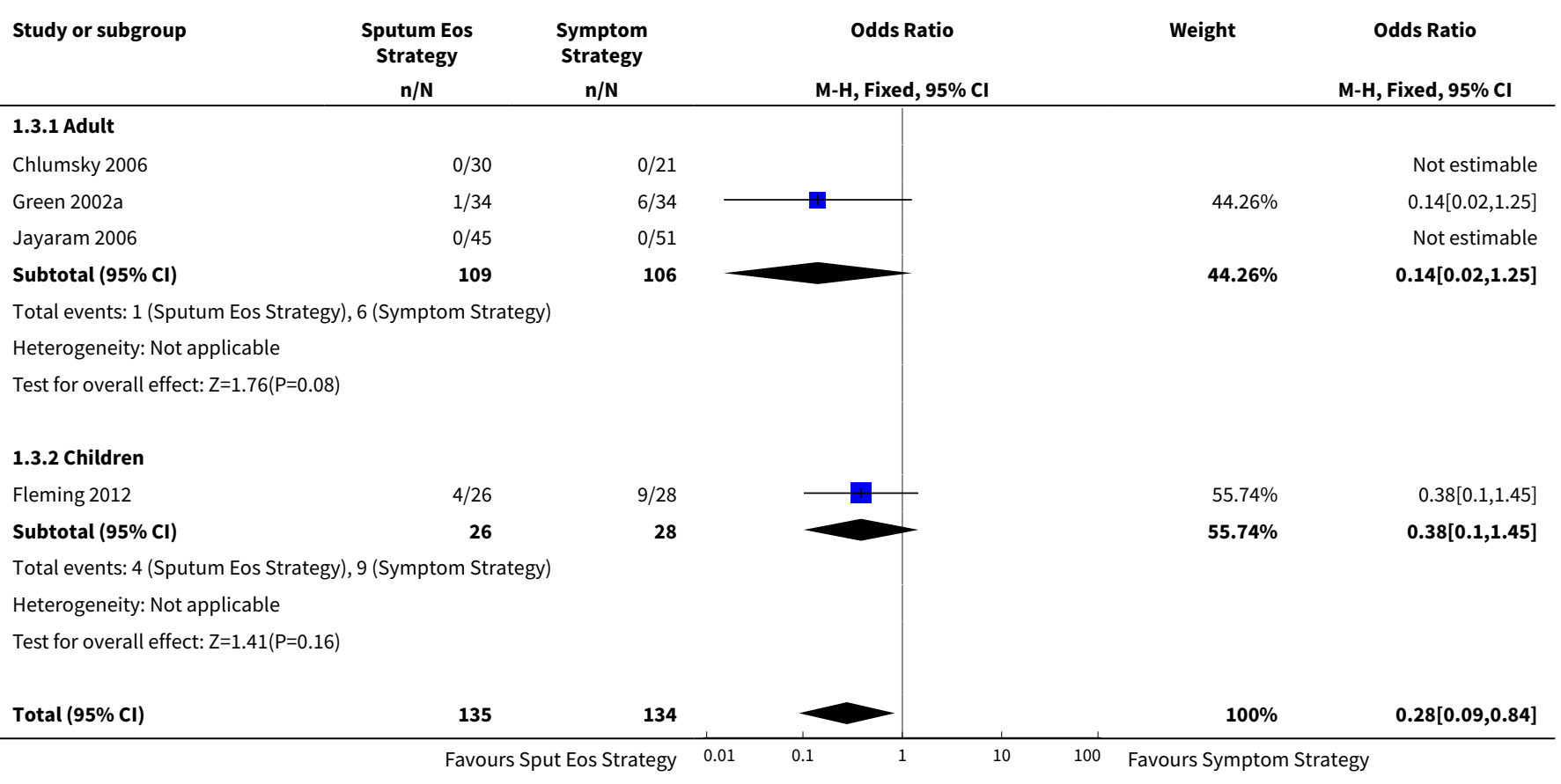




\begin{tabular}{cccc} 
Study or subgroup & $\begin{array}{c}\text { Sputum Eos } \\
\text { Strategy }\end{array}$ & $\begin{array}{c}\text { Symptom } \\
\text { Strategy }\end{array}$ & Odds Ratio \\
& $\mathrm{n} / \mathrm{N}$ & $\mathrm{n} / \mathrm{N}$ & $\mathrm{M}-\mathrm{H}$, Fixed, $95 \% \mathrm{Cl}$ \\
\hline
\end{tabular}

Total events: 5 (Sputum Eos Strategy), 15 (Symptom Strategy)

Heterogeneity: $\mathrm{Tau}^{2}=0 ; \mathrm{Chi}^{2}=0.6, \mathrm{df}=1(\mathrm{P}=0.44) ; \mathrm{I}^{2}=0 \%$

Test for overall effect: $\mathrm{Z}=2.27(\mathrm{P}=0.02)$

Test for subgroup differences: $\mathrm{Chi}^{2}=0.59, \mathrm{df}=1(\mathrm{P}=0.44), \mathrm{I}^{2}=0 \%$

$\begin{array}{lllllll}\text { Favours Sput Eos Strategy } & 0.01 & 0.1 & 1 & 10 & 100 & \text { Favours Symptom Strategy }\end{array}$

Analysis 1.4. Comparison 1 Asthma treatment tailored on sputum esoinophils versus symptoms, Outcome 4 Number of severe exacerbations requiring oral corticosteroids.

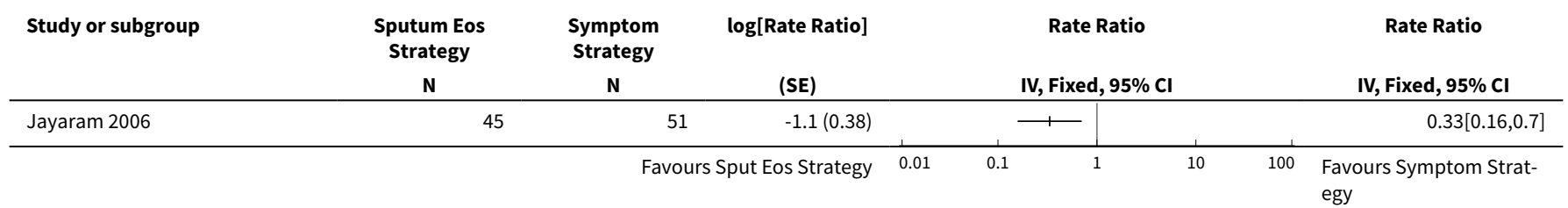

Analysis 1.5. Comparison 1 Asthma treatment tailored on sputum esoinophils versus symptoms, Outcome 5 Mild exacerbations over study period.

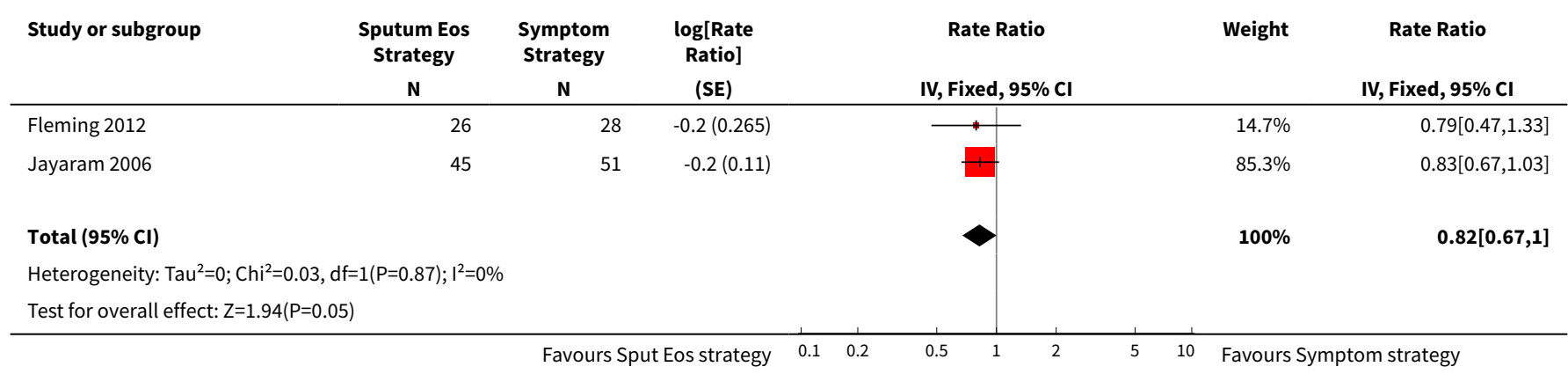

Analysis 1.6. Comparison 1 Asthma treatment tailored on sputum esoinophils versus symptoms, Outcome 6 Eosinophilic v Noneosinophilic exacerbations.

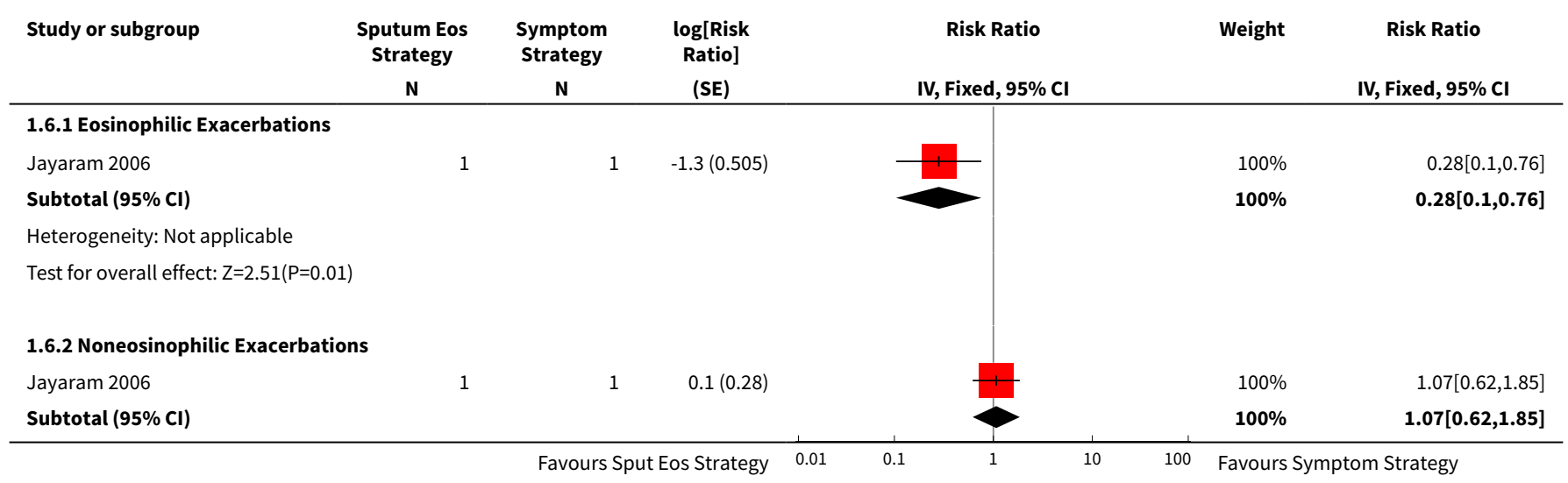




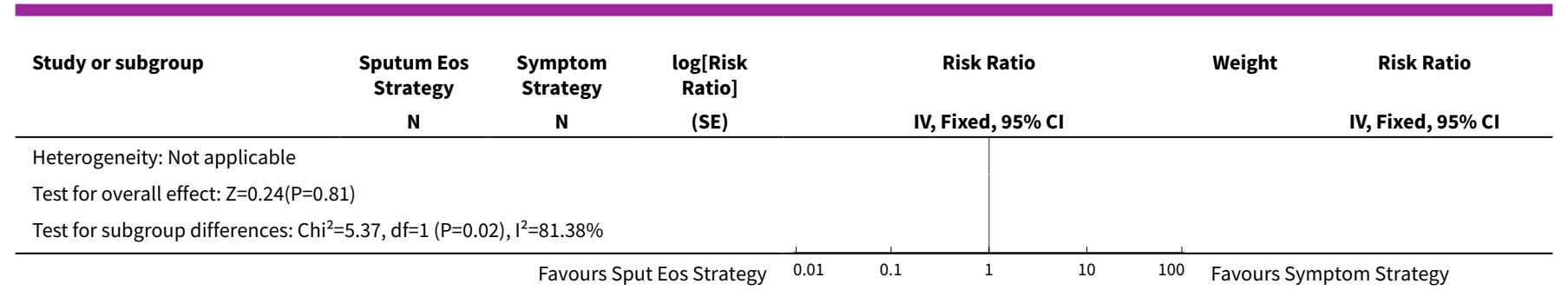

Analysis 1.7. Comparison 1 Asthma treatment tailored on sputum esoinophils versus symptoms, Outcome 7 Exacerbations subgrouped by asthma severity: Mild vs Severe.

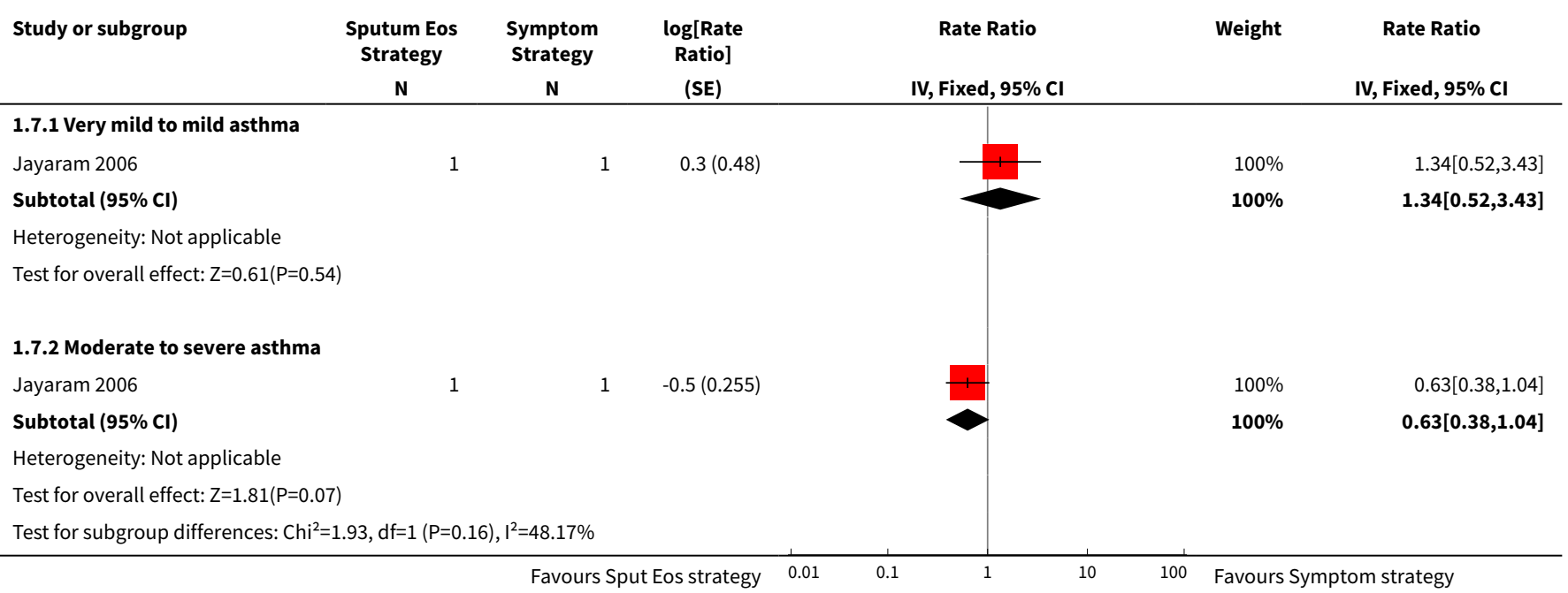

Analysis 1.8. Comparison 1 Asthma treatment tailored on sputum esoinophils versus symptoms, Outcome 8 Exacerbations subgrouped by asthma severity: Use of LABA.

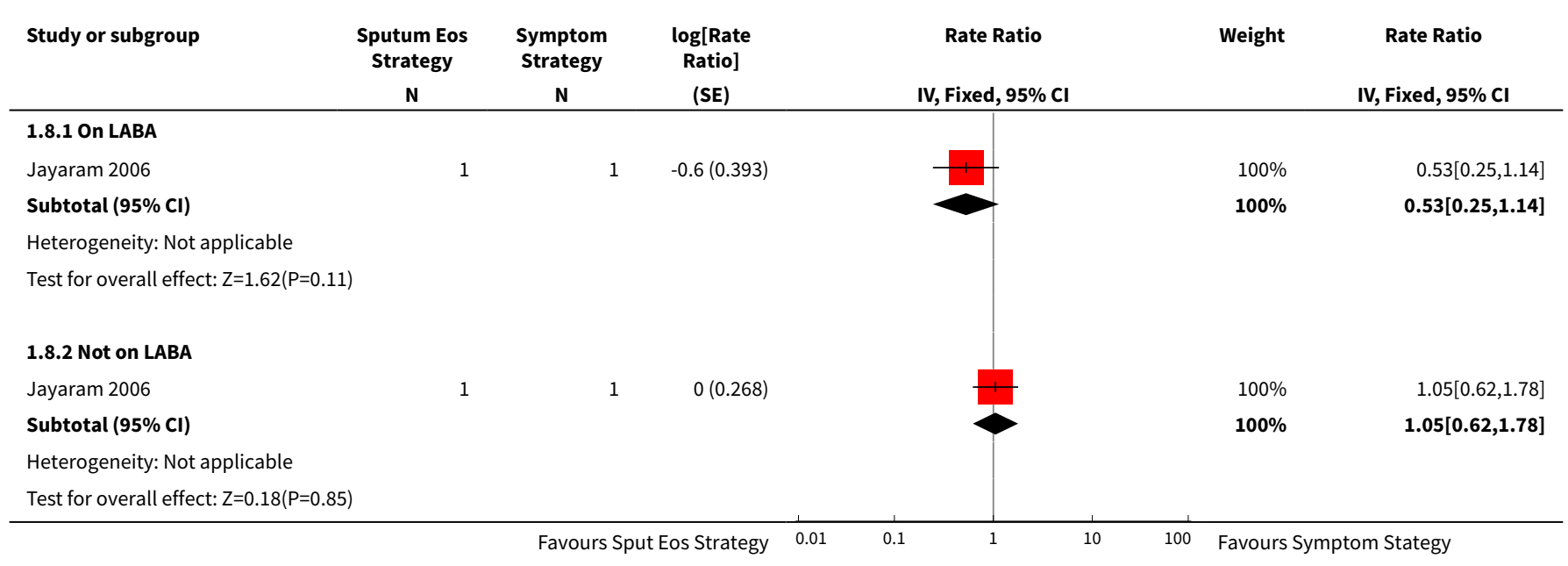


Analysis 1.9. Comparison 1 Asthma treatment tailored on sputum esoinophils versus symptoms, Outcome 9 Mean dose of inhaled corticosteroids per person per day (Bud equiv).

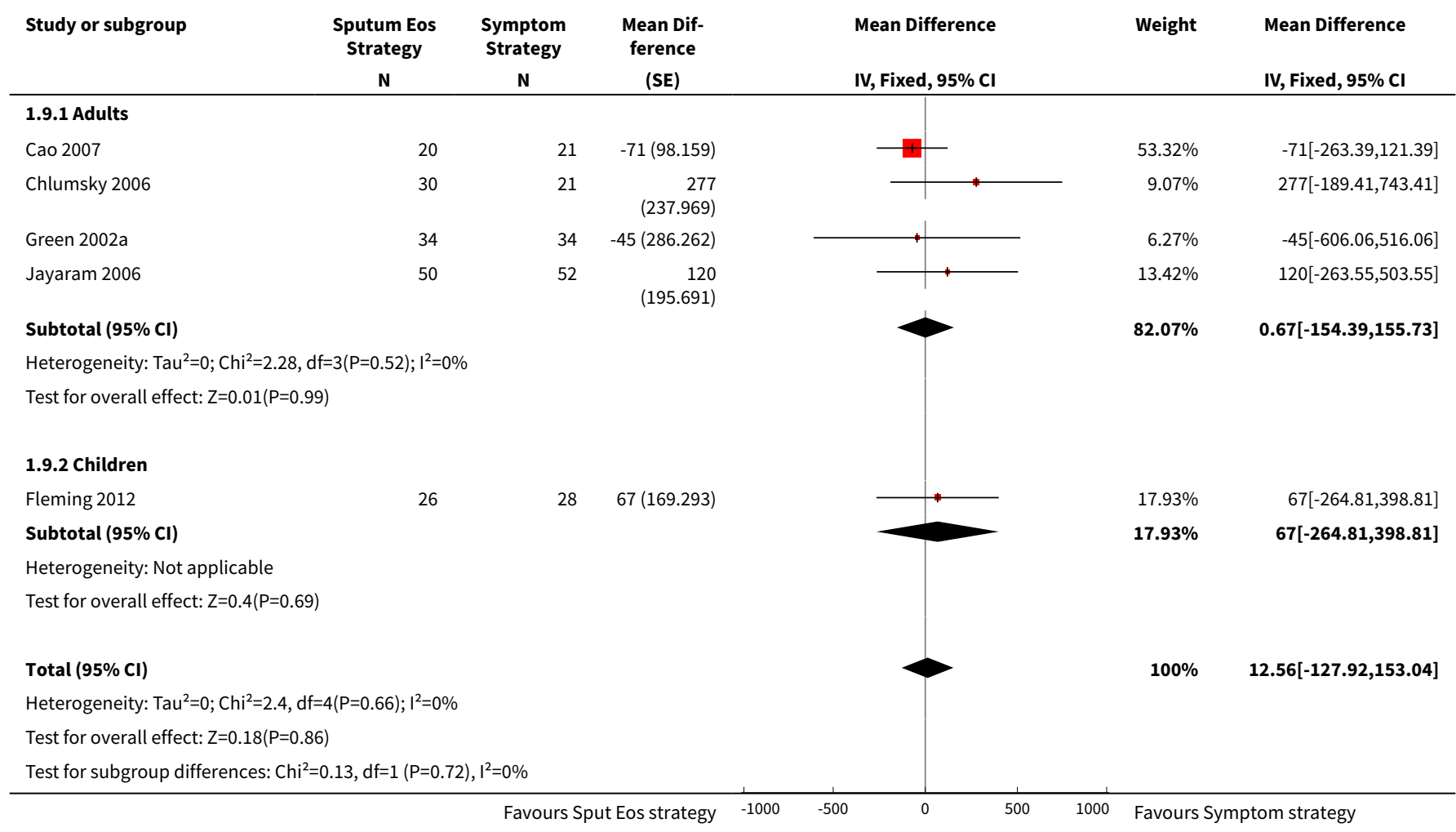

Analysis 1.10. Comparison 1 Asthma treatment tailored on sputum esoinophils versus symptoms, Outcome 10 Mean dose of oral corticosteroids per person per day.

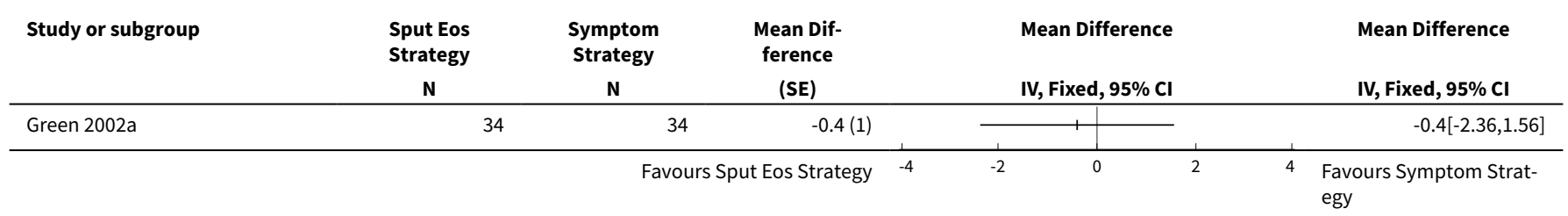

Analysis 1.11. Comparison 1 Asthma treatment tailored on sputum esoinophils versus symptoms, Outcome 11 Yearly cost per person (USD).

\begin{tabular}{|c|c|c|c|c|c|c|c|c|c|c|}
\hline \multirow{3}{*}{$\begin{array}{l}\text { Study or subgroup } \\
\text { Green } 2002 a\end{array}$} & \multicolumn{2}{|c|}{ Sputum Eos Strategy } & \multicolumn{2}{|c|}{ Symptom Strategy } & \multirow{2}{*}{\multicolumn{4}{|c|}{$\begin{array}{c}\text { Mean Difference } \\
\text { Fixed, } 95 \% \mathrm{Cl} \\
\end{array}$}} & & \multirow{3}{*}{$\begin{array}{l}\text { Mean Difference } \\
\text { Fixed, 95\% Cl } \\
-314[-941.27,313.27]\end{array}$} \\
\hline & \multirow{2}{*}{$\frac{\mathbf{N}}{34}$} & \multirow{2}{*}{$\frac{\text { Mean(SD) }}{2768(1096.2)}$} & \multirow{2}{*}{$\frac{\mathbf{N}}{34}$} & \multirow{2}{*}{$\frac{\text { Mean(SD) }}{3082(1510.2)}$} & & & & & & \\
\hline & & & & & - & & - & & & \\
\hline
\end{tabular}

\section{ADDITIONAL TABLES}


Table 1. Included studies definitions

\begin{tabular}{|c|c|c|c|c|}
\hline Study & Exacerbation definition & $\begin{array}{l}\text { Sputum eosinophil } \\
\text { cut-off (\%) }\end{array}$ & Control arm & $\begin{array}{l}\text { Study duration } \\
\text { (months) }\end{array}$ \\
\hline Cao 2007 & Unknown & $\begin{array}{l}\text { Decrease ICS < } 1 \\
\text { Keep same } 1 \text { to } 3 \\
\text { Increase ICS > } 3\end{array}$ & $\begin{array}{l}\text { "Standard clini- } \\
\text { cal } \\
\text { guidelines" }\end{array}$ & 6 \\
\hline Chlumsky 2006 & $\begin{array}{l}\text { Doubling of the frequency of symptoms } \\
\text { and/or number of puffs of rescue salbuta- } \\
\text { mol and/or reduction in morning PEF by } \\
30 \% \text { or more on at least } 2 \text { consecutive days. } \\
\text { A decrease in } \mathrm{FEV}_{1} \text { by }>30 \% \text { at any study vis- } \\
\text { it }\end{array}$ & $\begin{array}{l}\text { Decrease ICS } \leq 3 \\
\text { Keep same } 4 \text { to } 8 \\
\text { Increase ICS } \geq 8\end{array}$ & GINA guidelines & 18 \\
\hline Fleming 2012 & $\begin{array}{l}\text { Minor exacerbation: use of bronchodilators } \\
>5 \text { times/week (excl. routine or pre-exer- } \\
\text { cise) } \\
\text { Major exacerbation: deterioration requiring } \\
\text { high-dose OCS ( } \geq 20 \mathrm{mg} / \text { day) for at } \\
\text { least } 2 \text { days }\end{array}$ & $\begin{array}{l}\text { Decrease ICS < } 0.1 \\
\text { (or FeNO }<22 \mathrm{ppb} \text { ) } \\
\text { Keep same } 0.1 \text { to } 2.5 \\
\text { (or FeNO } 22 \text { to } 30 \mathrm{ppb)} \\
\text { Increase ICS }>2.5 \\
\text { (or FeNO }>30 \mathrm{ppb} \text { ) }\end{array}$ & $\begin{array}{l}\text { Based on num- } \\
\text { ber of major } \\
\text { exacerbations in } \\
\text { preceding } \\
3 \text { months and } \\
\text { SABA use in } \\
\text { preceding } 2 \\
\text { weeks }\end{array}$ & 12 \\
\hline Green 2002 & $\begin{array}{l}\text { Severe exacerbations: decrease in morning } \\
\text { PEF }>30 \% \text { on } 2 \text { or more consecutive days, or } \\
\text { deterioration in symptoms needing OCS. }\end{array}$ & $\begin{array}{l}\text { Decrease ICS < } 1 \\
\text { Keep same } 1 \text { to } 3 \\
\text { Increase ICS > } 3\end{array}$ & BTS guidelines & 12 \\
\hline Jayaram 2006 & $\begin{array}{l}\text { Worsening of symptoms requiring increased } \\
\text { use of SABA by } \geq 4 \text { puffs/day for a minimum } \\
\text { of } 48 \text { hours, or early morning wakening due } \\
\text { to respiratory symptoms }>2 \text { times/week, } \\
\text { with or without reduction in } \mathrm{FEV}_{1} \text { of at least } \\
20 \% \text {. } \\
\text { Severe exacerbation: course of OCS as de- } \\
\text { termined by study investigator. }\end{array}$ & $\begin{array}{l}\text { Decrease } I C S \leq 2 \\
\text { Increase ICS } \geq 2\end{array}$ & $\begin{array}{l}\text { Canadian Asth- } \\
\text { ma Consensus } \\
\text { Group Guidelines }\end{array}$ & 24 \\
\hline Malerba 2015 & $\begin{array}{l}\text { Moderate exacerbation: requiring an un- } \\
\text { scheduled visit with a course of OCS. } \\
\text { Severe exacerbation: hospital admission } \\
\text { and requiring > } 3 \text { days OCS. }\end{array}$ & $\begin{array}{l}\text { Sputum eosinophil (\%) } \\
\text { \& FeNO (ppb) } \\
\text { Decrease ICS }<2 \% \& \leq \\
10 \mathrm{pbb} \\
\text { Keep same } 2 \% \text { to } 3 \% \& \\
11 \text { to } 20 \mathrm{ppb} \\
\text { Increase ICS }>3 \% \& \geq 20 \\
\text { ppb }\end{array}$ & $\begin{array}{l}\text { Symptom scores, } \\
\text { use of SABA } \\
\text { and night time } \\
\text { symptoms }\end{array}$ & 24 \\
\hline
\end{tabular}

FeNO: exhaled nitric oxide; $\mathrm{FEV}_{1}$ : forced expiratory volume in one second; ICS: inhaled corticosteroids; OCS: oral corticosteroids; PEF: peak expiratory flow; ppb: parts per billion 


\section{APPENDICES}

\section{Appendix 1. Sources and search methods for the Cochrane Airways Group Specialised Register (CAGR) \\ Electronic searches: core databases}

\begin{tabular}{ll}
\hline Database & Frequency of search \\
\hline CENTRAL (the Cochrane Library) & Monthly \\
\hline MEDLINE (Ovid) & Weekly \\
\hline Embase (Ovid) & Weekly \\
\hline PsycINFO (Ovid) & Monthly \\
\hline CINAHL (EBSCO) & Monthly \\
\hline AMED (EBSCO) & Monthly \\
\hline
\end{tabular}

\section{Handsearches: core respiratory conference abstracts}

\begin{tabular}{ll}
\hline Conference & Years searched \\
\hline American Academy of Allergy, Asthma and Immunology (AAAAI) & 2001 onwards \\
\hline American Thoracic Society (ATS) & 2001 onwards \\
\hline Asia Pacific Society of Respirology (APSR) & 2004 onwards \\
\hline British Thoracic Society Winter Meeting (BTS) & 2000 onwards \\
\hline Chest Meeting & 2003 onwards \\
\hline European Respiratory Society (ERS) & $1992,1994,2000$ onwards \\
\hline International Primary Care Respiratory Group Congress (IPCRG) & 2002 onwards \\
\hline Thoracic Society of Australia and New Zealand (TSANZ) & 1999 onwards \\
\hline
\end{tabular}

\section{MEDLINE search strategy used to identify trials for the CAGR}

\section{Asthma search}

1. exp Asthma/

2. asthma\$.mp.

3. (antiasthma\$ or anti-asthma\$).mp.

4. Respiratory Sounds/

5. wheez\$.mp. 
6. Bronchial Spasm/

7. bronchospas\$.mp.

8. (bronch\$ adj3 spasm\$).mp.

9. bronchoconstrict\$.mp.

10. exp Bronchoconstriction/

11. (bronch\$ adj3 constrict\$).mp.

12. Bronchial Hyperreactivity/

13. Respiratory Hypersensitivity/

14. ((bronchial\$ or respiratory or airway\$ or lung\$) adj3 (hypersensitiv\$ or hyperreactiv\$ or allerg\$ or insufficiency)).mp.

15. ((dust or mite\$) adj3 (allerg\$ or hypersensitiv\$)).mp.

16. or/1-15

\section{Filter to identify RCTs}

1. exp "clinical trial [publication type]"/

2. (randomised or randomised).ab,ti.

3. placebo.ab,ti.

4. dt.fs.

5. randomly.ab,ti.

6. trial.ab,ti.

7. groups.ab,ti.

8. or/1-7

9. Animals/

10. Humans/

11.9 not (9 and 10)

12. 8 not 11

The MEDLINE strategy and RCT filter are adapted to identify trials in other electronic databases.

\section{Appendix 2. Search Strategies}

\#1 AST:MISC1

\#2 MeSH DESCRIPTOR Asthma Explode All

\#3 asthma*:ti,ab

\#4 \#1 or \#2 or \#3

\#5 MeSH DESCRIPTOR Sputum

\#6 MeSH DESCRIPTOR Mucus

$\# 7$ phlegm*

\#8 sputum $^{\star}:$ ti,ab

\#9 mucus*:ti,ab

$\# 10$ eosinophil*

\#11 MeSH DESCRIPTOR Eosinophils

\#12 airway ${ }^{\star}$ NEXT inflam*:ti,ab

$\# 13$ \#5 or \#6 or \#7 or \#8 or \#9 or \#10 or \#11 or \#12

$\# 14$ \#4 and \#13

[In search line \#1, MISC1 denotes the field in the record where the reference has been coded for condition, in this case, asthma]

Tailored interventions based on sputum eosinophils versus clinical symptoms for asthma in children and adults (Review) 


\section{Appendix 3. Search strategy to identify relevant trials from ClinicalTrials.gov and WHO trials portal}

"sputum eosinophils" AND "asthma" AND "clinical trials"

WHAT'S NEW

\begin{tabular}{lll}
\hline Date & Event & Description \\
\hline 15 February 2017 & $\begin{array}{l}\text { New citation required but conclusions } \\
\text { have not changed }\end{array}$ & $\begin{array}{l}\text { More data has been added to the review but the conclusions re- } \\
\text { main unchanged. }\end{array}$ \\
\hline 15 February 2017 & New search has been performed & $\begin{array}{l}\text { Updated to latest template. Searched and three new studies } \\
\text { added (Cao 2007; Fleming 2012; Malerba 2015). Change of au- } \\
\text { thorship. Many sections of the review redrafted. }\end{array}$ \\
\hline
\end{tabular}

\section{HISTORY}

Protocol first published: Issue 1, 2006

Review first published: Issue 2, 2007

\begin{tabular}{lll}
\hline Date & Event & Description \\
\hline 24 December 2009 & New search has been performed & $\begin{array}{l}\text { Searched for 2009 and inclusion of Risk of Bias and Summary of } \\
\text { Findings Tables. 1 study added to Ongoing studies. }\end{array}$ \\
\hline 11 May 2009 & Amended & Corrected data \\
\hline 12 December 2008 & New search has been performed & 2008 Searches and edited \\
\hline 1 September 2008 & Amended & Converted to new review format. \\
\hline 21 November 2007 & New search has been performed & New studies sought but none found \\
\hline 2 February 2007 & $\begin{array}{l}\text { New citation required and conclusions } \\
\text { have changed }\end{array}$ & Substantive amendment \\
\hline
\end{tabular}

\section{CONTRIBUTIONS OF AUTHORS}

For this updated review: HP and AC selected studies from search, and conducted data extraction, data analysis, and writing of review. Original review: all participated in selection of studies. HP and AC extracted data, performed analysis and wrote review. AL reviewed the manuscript In the previous review (Petsky 2007), AL, AK, CT reviewed manuscript.

\section{DECLARATIONS OF INTEREST}
HP: none known
AL: none known
AC: none known 


\section{SOURCES OF SUPPORT}

\section{Internal sources}

- Children's Hospital Foundation, Australia.

Support for research group via Program Grant for AC \& HP

\section{External sources}

- Australian Cochrane Airways Group Scholarship 2006, Australia.

- National Health Medical Research Council, Australia.

Support for AC and HP (post doctoral fellowship through CRE)

- Asthma Australia, Australia.

Early Career Fellowship for HP

\section{DIFFERENCES BETWEEN PROTOCOL AND REVIEW}

February 2017: The original protocol was written in 2006; since this time Cochrane methodology has become more rigorous. Therefore this updated review has considered these changes and adapted as necessary. The primary and secondary outcomes were changed for this update to be more specific.

\section{IN DEX TERMS}

\section{Medical Subject Headings (MeSH)}

*Eosinophils; Adrenal Cortex Hormones [therapeutic use]; Anti-Asthmatic Agents [ ${ }^{\star}$ therapeutic use]; Asthma [ ${ }^{\star}$ drug therapy] [pathology]; Disease Progression; Leukocyte Count; Randomized Controlled Trials as Topic; Sputum [ ${ }^{\star}$ cytology]

\section{MeSH check words}

Adolescent; Adult; Child; Humans 